\title{
A genetic toolkit for studying transposon control in the Drosophila melanogaster ovary
}

\author{
Mostafa F. ElMaghraby ${ }^{1,2,3}$, Laszlo Tirian ${ }^{1,3}$, Kirsten-André Senti ${ }^{1}$, Katharina Meixner ${ }^{1}$, \& Julius \\ Brennecke ${ }^{1,4}$
}

${ }^{1}$ Institute of Molecular Biotechnology of the Austrian Academy of Sciences (IMBA), Vienna BioCenter (VBC), Dr. Bohr-Gasse 3, 1030 Vienna, Austria

${ }^{2}$ Vienna BioCenter PhD Program, Doctoral School at the University of Vienna and Medical University of Vienna, 1030 Vienna, Austria

${ }^{3}$ these authors contributed equally to this work

${ }^{4}$ correspondence: julius.brennecke@imba.oeaw.ac.at

NGS Data on GEO: GSE174611 
bioRxiv preprint doi: https://doi org/10.1101/2021.06.29.450424; this version posted July 1, 2021. The copyright holder for this preprint (which

was not certified by peer review) is the author/funder, who has granted bioRxiv a license to display the preprint in perpetuity. It is made available under aCC-BY-NC-ND 4.0 International license.

\section{Running Title: A genetic toolkit for studying transposon control}

Key words: Drosophila, ovary, Gal4, germline, piRNA pathway, transposons, RNAi

\section{Corresponding author:}

Dr. Julius Brennecke

Institute of Molecular Biotechnology

Dr. Bohr-Gasse 3

1030 Vienna, Austria

+43179044

julius.brennecke@imba.oeaw.ac.at 


\section{ABSTRACT}

Argonaute proteins of the PIWI class complexed with PIWI-interacting RNAs (piRNAs) protect the animal germline genome by silencing transposable elements. One of the leading experimental systems for studying piRNA biology is the Drosophila melanogaster ovary. In addition to classical mutagenesis, transgenic RNA interference (RNAi), which enables tissue-specific silencing of gene expression, plays a central role in piRNA research. Here, we establish a versatile toolkit focused on piRNA biology that combines germline transgenic RNAi, GFP marker lines for key proteins of the piRNA pathway, and reporter transgenes to establish genetic hierarchies. We compare constitutive, pan-germline RNAi with an equally potent transgenic RNAi system that is activated only after germ cell cyst formation. Stage-specific RNAi allows us to investigate the role of genes essential for germline cell survival, for example nuclear RNA export or the SUMOylation pathway, in piRNAdependent and independent transposon silencing. Our work forms the basis for an expandable genetic toolkit provided by the Vienna Drosophila Resource Center. 


\section{INTRODUCTION}

Transposable elements (TEs) are mobile, selfish genetic elements that have parasitized almost all eukaryotic genomes and pose a threat to genome integrity (FESCHOTTE 2008; FEDOROFF 2012). In plants, fungi, and animals, small RNA silencing pathways are centrally involved in TE silencing, indicating an ancient function of RNA interference pathways in protecting the genome (MALONE AND HANNON 2009). In the animal germline, genome defense guided by small RNAs is carried out by Argonaute proteins of the PIWI-clade and their bound PIWI-interacting RNAs (piRNAs) (SIOMI $e t$ al. 2011; CZECH et al. 2018; OzATA et al. 2018). Most piRNAs originate from discrete genomic loci called piRNA clusters, which are rich in TE insertions (ARAVIN et al. 2007; BRENNECKE et al. 2007; HoUWING et al. 2007). Therefore, piRNAs can guide PIWI proteins to complementary TE transcripts, allowing their selective silencing at the transcriptional (nuclear PIWIs) and post transcriptional (cytoplasmic PIWIs) levels. Defects in the piRNA pathway are compatible with overall animal development but result in uncontrolled TE activity in gonads, DNA damage, ectopic recombination and sterility. As stable cell lines derived from germline cells are rare, and as the piRNA pathway can differ in different cell types, the arms race between TEs and the piRNA pathway must be studied within the context of a developing organism.

Drosophila oogenesis is one of the leading model systems for piRNA research. Two main cell types make up the fly ovary: (1) germline cells (germline stem cells, dividing cystoblast cells, nurse cells and oocyte) and (2) somatic support cells that form the stem cell niche and surround, nourish, and protect the germline cells (HUDSON AND COOLEY 2014). Both, germline and somatic cells of the ovary harbor a functional piRNA pathway. However, these pathways differ in several aspects. For example, germline cells express three PIWI clade Argonautes (nuclear Piwi, cytoplasmic Aubergine and Ago3), whereas somatic cells of the ovary express only nuclear Piwi (MALONE et al. 2009). The identity and biology of the genomic piRNA source loci also differ in the two cell types. piRNA clusters in the ovarian soma resemble canonical RNA Polymerase II transcription units with defined promoter, transcription start site and termination site (LAU et al. 2009; MALONE et al. 2009; GORIAUX et al. 2014; MOHN et al. 2014). Germline piRNA clusters are instead specified at the chromatin level by the action of Rhino, a member of the heterochromatin protein 1 (HP1) family that recruits germline specific variants of core gene expression factors to enable enhancer-independent transcription on both DNA strands within heterochromatic loci (KLATTENHOFF et al. 2009; MOHN et al. 2014; ZHANG et 
al. 2014; ANDERSEN et al. 2017). The resulting piRNA precursors are suppressed in splicing and canonical 3' end formation and are exported via a dedicated, germline specific RNA export route to the cytoplasmic, perinuclear piRNA processing sites known as nuage (CHEN et al. 2016; ELMAGHRABY et al. 2019; KNEUSS et al. 2019).

Defects in the germline piRNA pathway result in uncontrolled TE transposition and persistent activation of the DNA damage checkpoint. As a result, oocyte patterning pathways are disrupted, and eggs laid by piRNA pathway mutant flies have dorso-ventral polarity defects (THEURKAUF et al. 2006; KLATtENHOFF et al. 2007; SENTI et al. 2015; DuRdEVIC et al. 2018; WANG et al. 2018). Based on this phenotype, classic genetic screens have uncovered several piRNA pathway genes (Schupbach AND Roth 1994; CoOK et al. 2004; WeHR et al. 2006; ChEN et al. 2007; PANE et al. 2007; ZAMPARINI et al. 2011). With the development of transgenic RNAi and the establishment of genome-wide Drosophila RNAi libraries (DIETZl et al. 2007; HALEY et al. 2008; Ni et al. 2008; Ni et al. 2011), reverse genetic screens have systematically revealed piRNA pathway genes (CZECH et al. 2013; HANDLER et al. 2013). Depending on the Gal4 driver used, these screens were specific to the somatic or germline piRNA pathway. Together, they identified $\sim 40$ genes with specific functions in the piRNA pathway.

Transgenic RNAi in the germline is based on nanos-Gal4 driver lines that activate the expression of long or short RNA hairpin constructs targeting a gene of interest. The two most powerful transgenic RNAi setups for the germline are: (1) Combining the Maternal Triple Driver (MTD-Gal4; a combination of COG-Gal4 on the X-chromosome, NGT-Gal4 on the second, and nanos-Gal4 on the third chromosome; (GRIEDER et al. 2000) with transgenes harboring short hairpins (shRNA; microRNA mimics) under UAS-control (Valium20/22 backbones from the Harvard TRiP collection) (NI et al. 2011). And (2), the combination of a dual nanos-Gal4 driver line that activates the expression of UAS-controlled long dsRNA hairpins from the Vienna RNAi collection and of the RNAi-boosting protein Dcr-2 (DIETZL et al. 2007; WANG AND ElgIN 2011). Both approaches result in potent silencing of target gene expression throughout oogenesis, from primordial germ cells to germline stem cells to nurse cells and mature oocytes. 
While the pan-germline knockdown approaches have been instrumental for piRNA pathway research, they are not without limitations. For example, the piRNA pathway intersects with several general cellular processes such as SUMOylation, transcription, chromatin modification, and RNA export. Genetic disruption of these processes often leads to cell-lethal or pleiotropic phenotypes resulting in atrophic ovaries lacking germline cells, precluding meaningful analysis. Previous studies have identified and characterized alternative Gal4 driver lines that activate Gal4 expression in the female germline upon cystoblast differentiation (late germarium stages onward), leaving germline stem cells unaffected (STALLER et al. 2013). This allows genes with cell-essential functions to be studied as ovarian development proceeds to a sufficient extent.

Here, we first combine pan-oogenesis transgenic RNAi with marker lines expressing GFP-tagged piRNA pathway proteins with diverse molecular functions and sub-cellular localization. This toolkit provides a cell biology assay system for studying gene function within the germline piRNA pathway. We then introduce and characterize TOsk-Gal4, which causes strong Gal4 expression in the female germline immediately after germline cyst formation. TOsk-Gal4 is compatible with short and long hairpin RNAi libraries and allows efficient depletion of genes essential for cell survival without drastically affecting ovarian morphology and integrity. We combine TOsk-Gal4 with various genetic and molecular tools to study the interface between piRNA pathway, RNA export and protein SUMOylation. 


\section{MATERIALS \& METHODS}

\section{Fly Husbandry}

Flies were maintained at $25^{\circ} \mathrm{C}$ under light/dark cycles and $60 \%$ humidity. For ovary dissection, flies were kept in cages on apple juice plates with yeast paste for at least 5 days before dissection. All fly strains used and generated in this study are listed in Supplementary Table 1 and available via VDRC (https://stockcenter.vdrc.at/control/main).

\section{Generation of transgenic fly strains}

We generated fly strains harboring short hairpin RNA (shRNA) expression cassettes by cloning shRNA sequences into the Valium-20 vector (NI et al. 2011) modified with a white selection marker. Tagged fly stains were generated via insertion of desired tag sequences into locus-containing Pacman clones (VENKEN et al. 2009) via bacterial recombineering (EJSMONT et al. 2011).

\section{RNA Fluorescent In Situ Hybridization (RNA-FISH)}

5-10 ovary pairs were fixed in IF Fixing Buffer for 20 minutes at room temperature, washed three times for 10 minutes in PBX, and permeabilized in $70 \%$ ethanol at $4{ }^{\circ} \mathrm{C}$ overnight. Permeabilized ovaries were rehydrated in RNA-FISH wash buffer (10\% (v/w) formamide in $2 \times$ SSC) for 10 minutes. Ovaries were resuspended in $50 \mu 1$ hybridization buffer (10\% (v/w) dextran sulfate, 10\% (v/w) formamide in $2 \times$ SSC) supplemented with $0.5 \mu \mathrm{l}$ of $25 \mu \mathrm{M}$ RNA-FISH probe set solution (Stellaris; Supplementary Table 2 lists oligo sequences). Hybridization was performed at $37^{\circ} \mathrm{C}$ overnight with rotation. Next, ovaries were washed twice with RNA-FISH wash buffer for 30 minutes at $37^{\circ} \mathrm{C}$, and twice with 2xSSC solution for 10 minutes at room temperature. To visualize DNA, DAPI $(1: 10,000$ dilution) was included in the first $2 x S S C$ wash. Ovaries were mounted in $\sim 40 \mu 1$ Prolong Diamond mounting medium and imaged on a Zeiss LSM-880 confocal-microscope with AiryScan detector.

\section{Immunofluorescence staining of ovaries}

5-10 ovary pairs were dissected into ice-cold PBS and fixed in IF Fixing Buffer (4\% formaldehyde, $0.3 \%$ Triton X-100, 1x PBS) for 20 minutes at room temperature with rotation. Fixed ovaries were washed thrice with PBX (0.3\% Triton X-100, 1x PBS), 10 minutes each wash, and incubated in BBX (0.1\% BSA, $0.3 \%$ Triton X-100, 1x PBS) for 30 minutes for blocking. Primary antibodies diluted in $\mathrm{BBX}$ were added to ovaries and binding was performed at $4^{\circ} \mathrm{C}$ overnight. After three 10 minute- 
washes in $\mathrm{PBX}$, ovaries were incubated with secondary antibodies $(1: 1000$ dilution in $\mathrm{BBX})$ at $4{ }^{\circ} \mathrm{C}$ overnight. Afterwards, the ovaries were washed 4 times with PBX, with the second wash done with DAPI (1:50,000 dilution). To visualize the nuclear envelope, Alexa Fluor 647-conjugated wheat germ agglutinin (1:200 dilution in PBX; Thermo Fisher Scientific) was added after DAPI staining for 20 minutes. Ovaries were finally mounted in $\sim 40 \mu 1$ Prolong Diamond mounting medium and imaged on a Zeiss LSM-880 confocal-microscope with AiryScan detector. The resulting images processed using FIJI/ImageJ (SCHINDELIN et al. 2012). Supplementary Table 3 list antibodies used in this study.

\section{Western blot analysis}

10 ovary pairs were dissected in ice-cold PBS and homogenized with a plastic pestle in RIPA lysis buffer $(50 \mathrm{mM}$ Tris- $\mathrm{HCl} \mathrm{pH}$ 7.5, $150 \mathrm{mM} \mathrm{NaCl}, 1 \%$ Triton X-100, 0.5\% Na-deoxycholate, $0.1 \%$ SDS, $0.5 \mathrm{mM}$ EGTA, $1 \mathrm{mM}$ EDTA) freshly supplemented with $1 \mathrm{mM}$ Pefabloc, cOmplete Protease Inhibitor Cocktail (Roche), and $1 \mathrm{mM}$ DTT. The samples were spun down at 14,000 rpm for 5 minutes, and the homogenization step was repeated. After pooling both supernatants, samples were incubated on ice for 30 minutes and cleared by centrifugation at 14,000 rpm for 15 minutes. Protein concentrations were quantified by Bradford reagent, and $10 \mu \mathrm{g}$ protein were resolved by SDSpolyacrylamide gel electrophoresis and transferred to a $0.2 \mu \mathrm{m}$ nitrocellulose membrane (Bio-Rad). The membrane was blocked in 5\% skimmed milk powder in PBX (0.01\% Triton X-100 in PBS) and incubated with primary antibody overnight at $4{ }^{\circ} \mathrm{C}$ (Supplementary Table 3). After three washes with PBX, the membrane was incubated with HRP-conjugated secondary antibody for $1 \mathrm{~h}$ at room temperature, followed by three washes with PBX. Subsequently, the membrane was covered with Clarity Western ECL Blotting Substrate (Bio-Rad) and imaged using the ChemiDoc MP imaging system (Bio-Rad).

\section{RNA-Seq library preparation}

5 ovary pairs were homogenized with a plastic pestle in $200 \mu \mathrm{L}$ TRIzol reagent, and after homogenization $800 \mu \mathrm{L}$ TRIzol were added and incubated for 5 minutes at room temperature. 200 $\mu \mathrm{L}$ chloroform-isoamyl-alcohol (24:1; Sigma Aldrich) were added, and after vigorous shaking, samples were incubated for 5 minutes at room temperature. Next, samples were centrifuged at 12,000 $\mathrm{g}$ for 15 minutes at $4^{\circ} \mathrm{C}$. RNA was transferred from the upper aqueous phase using the Direct-zol RNA Miniprep kit (Zymo Research) with in-column DNaseI treatment according to manufacturer's 
instructions. rRNA depletion from $1 \mu \mathrm{g}$ total RNA was performed as described previously (ElMaghraby et al., 2019). Libraries were then cloned using the NEBNext Ultra II Directional RNA Library Prep Kit for Illumina (NEB), following the recommended kit protocol and sequenced on a NovaSeq 6000 - SR100 (Illumina).

\section{RT-qPCR analysis of transposon expression}

Five pairs of dissected ovaries were homogenized in TRIzol reagent followed by RNA purification according to the manufacturer's protocol. RNA was further purified with Direct-zol MiniPrep kit (Zymo Research) with DNase I treatment. $1 \mu \mathrm{g}$ of total RNA was reverse transcribed using the Maxima First Strand cDNA Synthesis kit (Thermo Fischer) following standard protocols. cDNA was used as template for RT-qPCR quantification of transposon mRNA abundances (for primer sequences see Supplementary Table 4).

\section{Data availability}

Table S1 list all fly stocks used and generated in the study. All fly stocks are available via the Vienna Drosophila Resource Center (VDRC). Next-Generation Sequencing data produced in this publication has been deposited to the NCBI GEO archive under the accession number GSE174611. Figure S1 indicates a crossing scheme for generating Gal4-based reporter lines. Table S2 lists of Stellaris RNAFISH probes used in this study. Table S2 and S3 list antibodies and oligo sequences used respectively. The authors affirm that all data necessary for confirming the conclusions of the article are present within the article, figures, and tables. 


\section{RESULTS AND DISCUSSION}

\section{Combining pan-oogenesis RNAi with GFP-based piRNA pathway marker transgenes}

Approximately forty proteins act in the Drosophila piRNA pathway. These factors serve different molecular functions and are localized to distinct subcellular locations in the nucleus (e.g. nucleoplasm or genomic piRNA source loci) and/or in the cytoplasm (e.g. outer mitochondrial membrane, perinuclear nuage). To visualize piRNA pathway proteins in whole mount ovary preparations by confocal microscopy, we generated transgenic fly lines carrying genomic rescue constructs with a FLAG-GFP tag at the N- or C-terminus of key piRNA pathway factors (four examples shown in Figure 1A). GFP-tagging allows accurate and semi-quantitative determination of the subcellular localization of a protein as it circumvents the limitations of antigen accessibility to primary and secondary antibodies. This is particularly relevant in late stage egg chambers (Figure 1B) or for factors enriched in peri-nuclear nuage such as Nxf3, Bootlegger, or Nibbler (Figure 1C).

To be able to analyze the subcellular localization of the different piRNA pathway proteins in flies with targeted genetic perturbations (using transgenic RNAi), we combined the established GFP marker lines with germline specific Gal4 drivers. The resulting fly strains can be crossed with genome-wide collections of UAS lines that allow expression of long or short double stranded RNA constructs targeting any gene of interest (available from VDRC or Bloomington/TRiP). Figure S1 shows the crossing schemes underlying the construction of MTD-Gal4 lines (compatible with short hairpin RNA (shRNA) UAS-lines) or nanos-Gal4 lines with a UAS-Dcr2 transgene (compatible with long hairpin RNA UAS-lines) harboring the various GFP reporter transgenes. The resulting stocks represent a core set of piRNA marker lines that can be crossed with available RNAi stocks and that are available from the VDRC (Table 1).

To illustrate the utility of the system, we focused on three subunits of the hexameric THO complex. THO is a key factor for nuclear mRNP quality control and, together with the RNA helicase UAP56 and the adaptor protein Aly/Ref1, functions as a central gatekeeper for nuclear mRNP export (HEATH et al. 2016). In germline cells, THO binds piRNA precursors derived from heterochromatic piRNA clusters in addition to mRNAs (ZHANG et al. 2012; HUR et al. 2016; ZHANG et al. 2018). Based on its central role in nuclear mRNA export, THO is also thought to be required for the export of piRNA precursors. Consistent with this, THO localizes broadly in the nucleoplasm in all cells, but is 
additionally enriched in germline cells at genomic piRNA source loci that are specified by the HP1 family protein Rhino (HUR et al. 2016; ZHANG et al. 2018).

We generated MTD-Gal4 lines expressing GFP-tagged THO subunits Tho2, Thoc5, or Thoc7, and crossed them with UAS-shRNA lines targeting rhino, thoc5 or thoc7. As expected, depletion of Rhino resulted in loss of Tho2, Thoc5, and Thoc7 accumulation in discrete nuclear foci, indicating that THO localization to piRNA clusters depends on Rhino (Figure 1D) (HUR et al. 2016; ZHANG et al. 2018). Loss of Thoc5 or Thoc7 revealed a strict co-dependence between both proteins for their stability, while Tho2 levels were only moderately affected in ovaries lacking Thoc5 or Thoc7 (Figures 1D-E). However, Tho2 localization to nuclear foci (piRNA clusters) strictly depended on Thoc5 and Thoc7 (Figure 1D). Consistent with a critical role of THO at piRNA clusters, flies lacking Thoc5 or Thoc7 in the germline, despite having morphologically normal ovaries, were sterile. Their sterility was presumably linked to defects in piRNA precursor export, supported by instability of Nxf3, the dedicated RNA export receptor for piRNA precursors (Figure 1F). In line with this, flies with strong hypomorphic thoc5 or thoc7 alleles are viable but show loss of piRNAs from Rhino-dependent clusters and are sterile (HUR et al. 2016; ZHANG et al. 2018). In contrast, depletion of Tho2 resulted in rudimentary ovaries, suggesting that Tho2 is genetically more important for mRNA export than the Thoc5 and Thoc7 subunits. These results are of interest in light of structural and biochemical studies of the human THO-UAP56 complex: Whereas Tho2 is part of the THO core assembly (alongside Hpr1 and Tex), Thoc5 and Thoc7 form an extended coiled coil that is responsible for dimerization of the hexameric THO complex (PUHRINGER et al. 2020). Our results illustrate that the combination of transgenic RNAi with GFP-transgenes is a powerful system to study protein function in the ovarian piRNA pathway and more generally during oogenesis.

A clear limitation of the pan-oogenesis Gal4 driver system is that genes, whose depletion is incompatible with oogenesis (e.g. tho2), cannot be studied. Transgenic RNAi of genes with cellessential functions results in rudimentary ovaries lacking detectable germline cells. Numerous genes (e.g. those involved in heterochromatin establishment, SUMOylation, nuclear RNA export) that are required for a functional piRNA pathway can therefore not be studied in this manner. Inspired by previous studies (STALLER et al. 2013; YAN et al. 2014), we set out to characterize alternative 
germline-specific Gal4 driver lines that, in combination with UAS-RNAi lines, are compatible with the analysis of cell-essential genes in the context of the ovarian piRNA pathway.

\section{Efficient and specific transgenic RNAi in the differentiating female germline}

Several germline specific genes are transcribed in differentiating cysts but not during embryonic, larval and pupal stages or in germline stem cells of the adult ovary. Gal4 driver lines exist for two of these genes: oskar (osk) and alpha-Tubulin at 67C ( $\alpha$ Tub67C) (Figure 2A) (BENTON AND ST Johnston 2003; TElley et al. 2012). The $\alpha$ Tub67C-Gal4 driver has been shown to induce efficient short-hairpin based RNAi in ovaries (STALLER et al. 2013; YAN et al. 2014). We set out to systematically compare osk-Gal4 and $\alpha T u b 67 C$-Gal4 to the pan-oogenesis MTD-Gal4. We first crossed each driver line with a fly line carrying a UASp-H2A-GFP transgene. In addition, we also induced H2A-GFP expression with traffic jam ( $t j)-G a l 4$, a somatic driver that is active in all somatic support cells of the ovary(TANENTZAPF et al. 2007; OLIVIERI et al. 2010). Western blot analysis indicated that H2A-GFP levels in ovary lysate were comparable (osk-Gal4) to, or even higher ( $\alpha$ Tub67C-Gal4), than those from the MTD-Gal4 crosses (Figure 2B). However, in contrast to the MTD-Gal4 crosses, no H2A-GFP was detectable in germline stem cells and early germline cysts in the germarium for the $o s k$-Gal4 or $\alpha T u b 67 C$-Gal4 crosses (Figures 2A, C). We consistently observed that H2A-GFP expression initiated slightly earlier (germarium region 2b) for osk-Gal4 than for $\alpha$ Tub67C-Gal4 (stage 2 egg chamber).

To evaluate the efficiency of the different drivers in inducing transgenic RNAi, we crossed them with flies carrying a very potent UAS-shRNA[GFP] transgene and one CRISPR-modified piwi allele harboring an N-terminal GFP-tag. As expected, MTD-Gal4 and $t j$-Gal4 induced strong depletion of GFP-Piwi in the entire ovarian germline or soma, respectively (Figure 2D). For osk-Gal4 and $\alpha T u b 67 C$-Gal4, GFP-Piwi levels were reduced from stage 2 egg chambers onwards and were undetectable in older egg chambers. As a more quantitative assay, we crossed the different Gal4 drivers with a UAS-shRNA[piwi] line and determined female sterility. shRNA-mediated depletion of Piwi with MTD-Gal4 resulted in 100\% sterility $(\mathrm{n}=200$ laid eggs). For $o s k$-Gal4 or $\alpha T u b 67 C$-Gal4, we observed near-complete sterility with occasional escapers. A driver line combining $\alpha T u b 67 C$ Gal4 and osk-Gal4 on the second chromosome, henceforth designated as TOsk-Gal4, resulted in complete sterility and was therefore used throughout this study. 
We compared TOsk-Gal4 and MTD-Gal4 in the context of the germline piRNA pathway and depleted the two central Argonaute proteins Piwi or Aubergine (Aub) with UAS-shRNA lines. Endogenous Piwi or Aub proteins were undetectable in all germline cells for MTD-Gal4 and from stage 2/3 egg chambers onwards for Tosk-Gal4 (shown for Aub in Figure 2E). For both Gal4 drivers, depletion of Piwi or Aub resulted in complete female sterility. To compare how depletion of Piwi with MTD-Gal4 versus TOsk-Gal4 impacts TE silencing, the central function of the germline piRNA pathway in Drosophila, we conducted RNA-seq experiments and, for selected TEs, RNA fluorescent in situ hybridization (FISH) experiments on ovaries with the different knockdown conditions. Overall, the same TEs that were de-repressed in ovaries depleted for Piwi during the entirety of oogenesis (MTDGal4) were also de-repressed, albeit at lower levels, in ovaries where transgenic RNAi was effective only from stage 3 egg chambers onwards (TOsk-Gal4) (Figure 3A). Examples for TEs exhibiting similar de-repression behavior are blood or HMS Beagle (Figures 3B). Mid and late stage egg chambers (where loss of Piwi is indistinguishable in MTD- versus TOsk-Gal4 crosses) contribute the bulk of the ovary mass and RNA. We therefore argue that the milder TE de-repression in the TOskGal4 crosses is not due to differences in knockdown efficiency, but rather due to delayed TE desilencing upon loss of piRNA pathway activity. Piwi-mediated heterochromatin formation at TE loci likely contributes to this pattern. In agreement with this, steady state RNA levels for the LTR retrotransposon $m d g 3$, which is primarily repressed via Piwi-mediated heterochromatin formation (SENTI et al. 2015) and whose steady state RNA levels were more than 350-fold elevated upon MTDGal4-mediated Piwi knockdown, did not change more than 2 -fold when Piwi was depleted with Tosk-Gal4 (Figures 2A, C). Taken together, TOsk-Gal4 allows potent transgenic RNAi in germline cells of maturing egg chambers. In the case of the piRNA pathway, this results in a temporal delay in TE de-repression compared to a pan-germline knockdown.

\section{Intersection points between piRNA pathway and essential cellular processes}

To evaluate the utility of the TOsk-Gal4 transgenic RNAi system, we investigated biological processes that are required for transposon silencing and for cellular viability. We focused on the nuclear RNA export factors UAP56 and Nxf1, the protein exporter Crm1 (ZHANG et al. 2012; ELMAGHRABY et al. 2019; KNEUSS et al. 2019), and on the protein SUMOylation machinery with the E1 activating enzyme Uba2-Aos1 and the E3 Ligase Su(var)2-10 (NINOVA et al. 2020). Depletion of any of these factors with MTD-Gal4 resulted in rudimentary ovaries, precluding any meaningful 
analysis as these lacked germline tissue, evidenced by the absence of Aub expressing cells (Figures 4, 5A; shown for UAP56, Crm1, Sbr). Crossing the same set of UAS-shRNA lines with the ToskGal4 driver yielded flies with partially restored ovarian morphology and germline development.

Nuclear export of mRNA and piRNA precursors, both transcribed by RNA Polymerase II, requires the THO complex and the RNA Helicase UAP56 (ZHANG et al. 2012; HuR et al. 2016; ZHANG et al. 2018; ElMaghraby et al. 2019). Together, these proteins license the loading of the RNA cargo onto a specific nuclear export receptor belonging to the NXF protein family (Nxf1 for mRNA, Nxf3 for piRNA precursors), which subsequently shuttles its respective RNA cargo through nuclear pore complexes into the cytoplasm (KOHLER AND HURT 2007; ELMAGHRABY et al. 2019; KNEUSS et al. 2019). Consistent with their central role in nuclear mRNA export, RNAi-mediated depletion of Nxf1 (Drosophila Small bristles; Sbr) or UAP56 with MTD-Gal4 resulted in ovaries lacking germline cells (absence of Aub expressing cells; Figure 5A). Depletion of UAP56 or Sbr with TOsk-Gal4 also yielded sterile females. These flies, however, contained larger ovaries with clearly developing egg chambers, hence permitting molecular analyses (Figures 4, 5A). We performed RNA-seq experiments on ovaries where UAP56 was depleted with TOsk-Gal4. Besides many genes that were de-regulated compared to control ovaries, numerous piRNA pathway repressed TEs were de-silenced (Figure 5B). In contrast, TEs were not de-repressed in ovaries depleted of the essential mRNA export receptor Sbr (Figure 5C) supporting a direct role of UAP56 in the piRNA pathway, beyond nuclear export of mRNAs encoding for piRNA pathway proteins. These findings highlight the dual role of UAP56 as a central gate keeper to feed RNA cargo into two distinct nuclear export receptors, Nxf1-Nxt1 for mRNAs and Nxf3-Nxt1 for Rhino dependent piRNA precursors.

As a second intersection point between piRNA pathway and essential cellular processes, we chose piRNA-guided heterochromatin formation. The nuclear Argonaute protein Piwi, guided by its bound piRNAs, induces transcriptional gene silencing and specifies the local formation of heterochromatin at genomic TE insertions (WANG AND ELGIN 2011; SIENSKI et al. 2012; LE THOMAS et al. 2013; ROZHKOV et al. 2013). This process depends on transcription of a piRNA-complementary nascent transcript. To mediate silencing, piRNA-loaded Piwi requires a handful of piRNA pathway-specific factors (Gtsf1/Asterix, Maelstrom, SFiNX complex) as well as factors of the general heterochromatin machinery that the piRNA pathway taps into (CZECH et al. 2018; NINOVA et al. 2019). Depletion of 
these general factors via MTD-Gal4 driven transgenic RNAi yields rudimentary ovaries with absent germline tissue. To explore the utility of the TOsk-Gal4 system, we focused on the protein SUMOylation pathway that is involved in numerous chromatin-related processes and that is required for Piwi-mediated transcriptional silencing and heterochromatin formation (GAREAU AND LIMA 2010; JENTSCH AND PSAKHYE 2013; NINOVA et al. 2020).

Protein SUMOylation requires E1 and E2 enzymes. Drosophila expresses a single E1 enzyme (Aos1Uba2) and a single E2 enzyme (Lwr), which in a stepwise manner transfer a SUMO moiety onto a target Lysin of the substrate. A handful of E3 ligases potentiate the SUMOylation process in a substrate specific manner. Recent work has uncovered a critical role for the E3 ligase Su(var)2-10, and hence SUMOylation, in Piwi-mediated heterochromatin formation (NINOVA et al. 2020). Depletion of Uba2, Aos1 or Su(var)2-10 with MTD-Gal4 was incompatible with GSC survival and oogenesis (Figure 4) (YAN et al. 2014). We therefore used TOsk-Gal4 driven transgenic RNAi to probe for a requirement for SUMOylation in the piRNA pathway. Piwi-mediated transcriptional silencing and heterochromatin formation can be mimicked by experimental tethering of the SFiNX complex to a nascent transcript using the $\lambda \mathrm{N}-$ boxB system (Figure 6A) (SIENSKI et al. 2015; YU et al. 2015). In ovaries from flies that ubiquitously express a GFP reporter with boxB sites and that harbor the TOsk-Gal4 driver and a UASp- $\lambda$ N-Panoramix (SFiNX subunit) construct, GFP expression was silenced specifically in the germline from stage 3 egg chambers onwards (Figure 4B). Simultaneous expression of shRNA constructs targeting Piwi, which acts upstream of SFiNX, had no impact on GFP silencing. Similarly, targeting the mRNA exporter Sbr (Nxf1) did not interfere with SFiNX function, supporting the specificity of the assay. In contrast, depletion of the SUMOylation machinery (Aos1, Uba2 or $\mathrm{Su}(\mathrm{var}) 2-10$ ) restored GFP expression confirming that protein SUMOylation is required for SFiNX-mediated heterochromatin formation (Figure 6B).

To obtain a more quantitative and systematic impact of the SUMOylation pathway on TE silencing in the female germline, we performed RNA-seq experiments on ovaries depleted (via TOsk-Gal4) for Piwi, Uba2, Aos1 or Su(var)2-10 and compared TE RNA levels to those in control ovaries. Depletion of Piwi or Su(var)2-10 resulted in overall similar TE silencing defects (Figure 6C). When comparing TE transcript levels in Piwi depleted ovaries to those in ovaries depleted for the SUMO E1-ligase subunits Aos1 or Uba2, a similar set of TEs showed increased expression (Figure 6D). However, the 
$R 1$ and $R 2$ retrotransposons, two LINE elements that integrate specifically into rDNA units, were strong outliers as they showed nearly exclusive de-repression in ovaries lacking Aos1 or Uba2. In Aos 1 or Uba 2 depleted ovaries, steady state RNA levels of $R 1$ and $R 2$ reached enormous levels and were among the most abundant cellular transcripts (Figures 6D, E). $R 1$ or $R 2$ showed no de-repression in ovaries lacking Piwi (even when depleted via the MTD-Gal4 driver) although germline Piwi is loaded with $R 1$ and $R 2$ derived piRNAs. In agreement with a recent report (LuO et al. 2020), our data indicate that the SUMOylation pathway is integral for silencing $R l$ and $R 2$, likely in a piRNAindependent and to a large extent also in a $\mathrm{Su}(\mathrm{var}) 2-10$ independent manner.

\section{A TOsk-Gal4 system for long dsRNA hairpins and earlier expression}

During our studies on the transgenic RNAi system using TOsk-Gal4, we encountered two technical aspects that warranted further modifications. While TOsk-Gal4 was highly efficient in depleting target genes using shRNA lines (e.g. TRIP collection), it was very inefficient with long dsRNA hairpin lines (VDRC collection). For example, when we crossed TOsk-Gal4 to UAS lines harboring long dsRNA hairpins targeting the SUMO-pathway, the resulting females were fertile, in stark contrast to crosses to shRNA lines targeting the same genes. This was reminiscent of the panoogenesis Gal4 driver system where efficient transgenic RNAi using long hairpin constructs requires the co-expression of the siRNA generating ribonuclease Dcr-2 (WANG AND ELGIN 2011). Indeed, when we combined TOsk-Gal4 with an X-chromosomal UAS-Dcr-2 transgene, knockdown of Smt3 (Drosophila SUMO) as well as of the single E2 SUMO-conjugating enzyme Ubc9 (encoded by the $l w r$ gene) yielded sterile females. These exhibited severe reductions in Smt3 levels specifically in the germline (for the smt 3 knockdown) and the characteristic strong de-repression of the $R 1$ and $R 2$ elements (Figure 6A, B). Given the almost genome wide collection of dsRNA hairpin lines at the VDRC, the TOsk-Gal4 > UAS-Dcr-2 combination stock will enable systematic genetic screens targeting genes that with a pan-oogenesis knockdown would yield rudimentary ovaries, often lacking germline tissue.

We finally considered the timing of oogenesis in respect to the onset of transgenic RNAi. The developmental process from germline stem cell division to mature egg takes nearly one week (HORNE-BADOVINAC AND BILDER 2005; He et al. 2011). Up to four days are spent during the germarium stages, meaning before the onset of measurable depletion of target proteins using TOsk- 
Gal4. Though extraordinary efficient in depleting even abundant factors like Piwi or Smt3, this means that the time window of efficient transgenic RNAi is around two to three days. To extend this effective knockdown period, we turned to the bam-Gal4 driver, which is expressed in a narrow time period of around one day at the onset of cystoblast division (Figure 7C) (CHEN AND MCKEARIN 2003). When combining bam-Gal4 with TOsk-Gal4 (BamTOsk-Gal4), the knockdown of GFP-Piwi with an shRNA line against GFP indicated severe loss of Piwi already at the germarium stage $2 b$, thereby extending the entire knockdown window of this triple driver to three to four days (Figure 7D). For a direct comparison of the various Gal4 driver combinations, we used the $\operatorname{sh}[s b r]$ line that leads to a highly potent depletion of the cell-essential mRNA export receptor Sbr (Drosophila Nxf1) (Figure 7E). Depletion of Sbr with the pan-oogenesis MTD-Gal4 driver resulted in the complete absence of germline tissue (no Aub positive cells). Depletion by TOsk-Gal4 resulted in phenotypically normal germaria and two to four additional egg chambers per ovariole. The BamTOsk-Gal4 cross resulted in an intermediate phenotype with normal germaria but only one additional egg chamber per ovariole. Thus, the BamTOsk-Gal4 driver represents an ideal driver to study gene function in the differentiating female germline via transgenic RNAi.

Taken all together, our work provides a versatile, highly specific and powerful genetic toolkit that permits tissue specific RNAi at various stages of oogenesis in conjunction with GFP markers for the visualization of subcellular structures. While our focus was on piRNA biology, the presented approach is applicable to any expressed gene in the ovarian germline and complements previously established assays based on MTD-Gal4 or a double $\alpha$ Tub67C-Gal4 driver (STALLER et al. 2013; YAN et al. 2014). Through the compatibility with genome wide short and long UAS-dsRNA lines available from the Bloomington stock center or the VDRC, our work enables reverse genetic screens for the involvement of cell-essential factors in specific biological processes. 


\section{ACKNOWLEDGEMENTS}

We thank D. Handler and M. Gehre for help with bioinformatics and computational analyses, the IMBA/IMP/GMI core facilities, in particular BioOptics for support, the Vienna Biocenter Core Facilities (VBCF) for providing NGS, COVID-19 testing, and fly stocks and husbandry services (VDRC). Imre Gaspar and Daniel St. Johnston provided fly stocks. We sincerely thank Clemens Plaschka and Brennecke lab members for support and insightful discussions.

\section{FUNDING}

The Brennecke lab is supported by the Austrian Academy of Sciences, the European Research Council (ERC-2015-CoG - 682181), and the Austrian Science Fund (F 4303 and W1207). M.F.E is supported by a DOC Fellowship from the Austrian Academy of Sciences.

\section{AUTHOR CONTRIBUTIONS}

The project was conceived by JB, MFE and LT. MFE and LT performed all molecular biology and genetics experiments. KAS conceptualized the BamTOsk-Gal4 driver and KAS and KM generated essential reagents and fly stocks. JB supervised the study and MFE, LT and JB wrote the paper with input from all authors.

\section{DECLARATION OF INTERESTS}

The authors declare no competing interests. 


\section{FIGURE LEGENDS}

\section{Figure 1: Pan-oogenesis RNAi with GFP-based piRNA pathway marker transgenes}

(A) Confocal images (scale bars: $5 \mu \mathrm{m}$ ) showing localization of GFP-tagged Zucchini (mitochondrial membrane), Deadlock (piRNA clusters), Aubergine (cytoplasm with nuage enrichment), and Piwi (nuclear) in germline nurse cell nuclei (nuclear envelope labelled with WGA in magenta).

(B) Confocal image (scale bar: $25 \mu \mathrm{m}$ ) showing GFP-Piwi localization (green) in an ovariole stained also with anti-Piwi antibody (red). To the right, an enlarged early egg chamber with good overlap between GFP and immunofluorescence (IF) signals (top) and nurse cell nuclei from an older egg chamber where the GFP signal dominates due to reduced antibody penetration (bottom) are shown.

(C) Confocal image (scale bar: $3 \mu \mathrm{m}$ ) showing a nurse cell nucleus expressing Bootlegger-GFP (green) from the endogenous locus stained with an anti-Bootlegger antibody (red). Overlap between GFP and IF signals is apparent in nuclear foci, yet very poor in nuage.

(D) Confocal images of egg chambers (scale bars: $25 \mu \mathrm{m}$ ) displaying localization of GFP-tagged Thoc7, Thoc5, or Tho2 (greyscale) in the indicated germline knockdown (GLKD) conditions (nuclei highlighted in red are enlarged).

(E-F) Western blot analysis indicating levels of Thoc7 and Thoc5 (E), or Nxf3 (F) in ovary lysates from flies with indicated genotype (anti ATP-synthase blots served as loading control).

\section{Figure 2: Efficient and specific transgenic RNAi in the differentiating female germline.}

(A) Cartoon of a Drosophila ovariole with somatic cells in green and germline cells in beige; egg chamber stages are indicated above and a magnified view of the germarium with stem cell niche is shown below.

(B) Western blot analysis indicating levels of H2A-GFP expressed with indicated Gal4 drivers (anti ATP-synthase blot served as loading control).

(C) Confocal images (scale bars: $50 \mu \mathrm{m}$ ) showing ovarioles expressing H2A-GFP (greyscale) driven by indicated germline and soma Gal4 drivers (captions to the right show enlarged germaria).

(D) Confocal images (scale bars: $50 \mu \mathrm{m}$ ) showing ovarioles expressing GFP-Piwi (greyscale) in the indicated genotypes (captions to the right show enlarged germaria).

(E) Top: Confocal images (scale bars: $50 \mu \mathrm{m}$ ) showing ovarioles stained for Aubergine in the indicated genotypes (captions to the right show enlarged germaria). Bottom: Western blot analysis 
indicating levels of endogenous Aubergine in ovarian lysates from flies with the indicated genotypes (anti ATP-synthase blot served as loading control).

\section{Figure 3: Comparison of MTD-Gal4 and TOsk-Gal4 driven transgenic RNAi}

(A) Scatter plot showing log2 fold changes (respective to control) of TE steady state RNA levels in ovaries where germline Piwi was depleted using MTD-Gal4 or TOsk-Gal4.

(B and C) Confocal images (scale bars: $10 \mu \mathrm{m}$ ) of egg chambers with indicated genotype stained for the TEs blood or HMS-Beagle (B), or for $m d g 3$ (C) using RNA-FISH (yellow; DAPI: magenta).

\section{Figure 4: Transgenic RNAi of essential genes with TOsk-Gal4}

Bright field images (scale bar for all images: $200 \mu \mathrm{m}$ ) showing ovarian morphology from flies of the indicated genotype (to the left: MTD-Gal4 crosses; to the right: TOsk-Gal4 crosses).

\section{Figure 5: Dual role of UAP56 in mRNA export and transposon defense.}

(A) Confocal images (scale bars: $100 \mu \mathrm{m}$ ) showing whole ovaries from flies of indicated genotypes stained with anti-Aubergine antibody (red); DNA stained with DAPI (blue).

(B) Volcano plot showing fold changes in steady state mRNA (black dots) and TE transcript levels (red dots) in ovaries from TOsk-Gal4 > sh[UAP56] flies versus control flies $(\mathrm{n}=2$ biological replicates).

(C) qRT-PCR analysis showing fold changes in steady state TE transcript levels in ovaries from flies with indicated genotype qRT-PCR ( $\mathrm{n}=2$ biological replicates; normalized to $r p 49$ mRNA levels).

\section{Figure 6: The SUMO machinery is required for TE repression in the germline}

(A) Cartoon depicting the transgenic RNA-tethering reporter based on the $\lambda N$-boxB system. The $\alpha$ tubulin promoter expresses GFP in all cells, and the 3' UTR harbors five boxB sites to allow tethering of $\lambda \mathrm{N}-\mathrm{Panx}$ to the reporter mRNA.

(B) Confocal images (scale bar: $50 \mu \mathrm{m}$ ) showing GFP signal (greyscale) in egg chambers expressing the GFP-boxB reporter plus $\lambda \mathrm{N}$-Panx and the indicated shRNAs specifically in the germline using TOsk-Gal4 (somatic cells serve as control).

(C-D) Scatter plots based on RNA-seq data showing $\log 2$ fold changes (relative to control) in TE steady state transcript levels in ovaries from flies of the indicated genotype. 
(E) Confocal images (scale bar: $10 \mu \mathrm{m}$ ) of egg chambers from flies with indicated genotype showing $R 1$ transposon mRNA using RNA-FISH (yellow; DAPI: magenta).

\section{Figure 7: Extensions of the TOsk-Gal4 system}

(A) Confocal images (scale bar: $10 \mu \mathrm{m}$ ) showing ovarioles from flies with indicated genotype stained with anti-Smt3 antibody (greyscale).

(B) Confocal images (scale bar: $10 \mu \mathrm{m}$ ) of egg chambers from flies with indicated genotype showing $R 1$ transcripts (RNA-FISH: yellow, DAPI: magenta).

(C) Confocal image showing ovarioles expressing H2A-GFP driven by the bam-Gal4 driver.

(D) Confocal image (scale bar: $25 \mu \mathrm{m}$ ) showing GFP-Piwi levels (greyscale) in an ovariole expressing an sh[GFP] transgene with BamTOsk-Gal4 (inset shows the enlarger germarium; somatic cells serve as internal control).

(D) Confocal images showing whole ovaries (top row; scale bar: $100 \mu \mathrm{m}$ ) from flies of indicated genotype stained with anti-Aubergine antibody (red); DNA stained with DAPI (blue). Early oogenesis regions are highlighted in the bottom row (scale bar: $25 \mu \mathrm{m}$ ).

\section{Figure S1: Crossing scheme to generate marker lines with Gal4 Drivers.}

(A) Scheme for construction of MTD-Gal4 lines with compatible with short hairpin RNA (shRNA) UAS-lines.

(B) Scheme for construction of nanos-Gal4 lines with a UAS-Dcr-2 transgene compatible with long hairpin RNA UAS-lines. 


\section{REFERENCES}

Andersen, P. R., L. Tirian, M. Vunjak and J. Brennecke, 2017 A heterochromatin-dependent transcription machinery drives piRNA expression. Nature 549: 54-59.

Aravin, A. A., R. Sachidanandam, A. Girard, K. Fejes-Toth and G. J. Hannon, 2007 Developmentally regulated piRNA clusters implicate MILI in transposon control. Science 316: 744-747.

Benton, R., and D. St Johnston, 2003 Drosophila PAR-1 and 14-3-3 inhibit Bazooka/PAR-3 to establish complementary cortical domains in polarized cells. Cell 115: 691-704.

Brennecke, J., A. A. Aravin, A. Stark, M. Dus, M. Kellis et al., 2007 Discrete Small RNAGenerating Loci as Master Regulators of Transposon Activity in Drosophila. Cell 128: 1089-1103.

Chen, D., and D. M. McKearin, 2003 A discrete transcriptional silencer in the bam gene determines asymmetric division of the Drosophila germline stem cell. Development 130: 1159-1170.

Chen, Y., A. Pane and T. Schupbach, 2007 Cutoff and aubergine mutations result in retrotransposon upregulation and checkpoint activation in Drosophila. Curr Biol 17: 637-642.

Chen, Y. A., E. Stuwe, Y. Luo, M. Ninova, A. Le Thomas et al., 2016 Cutoff Suppresses RNA Polymerase II Termination to Ensure Expression of piRNA Precursors. Mol Cell 63: 97109.

Cook, H. A., B. S. Koppetsch, J. Wu and W. E. Theurkauf, 2004 The Drosophila SDE3 homolog armitage is required for oskar mRNA silencing and embryonic axis specification. Cell 116: 817-829.

Czech, B., M. Munafo, F. Ciabrelli, E. L. Eastwood, M. H. Fabry et al., 2018 piRNA-Guided Genome Defense: From Biogenesis to Silencing. Annu Rev Genet 52: 131-157.

Czech, B., J. B. Preall, J. McGinn and G. J. Hannon, 2013 A Transcriptome-wide RNAi Screen in the Drosophila Ovary Reveals Factors of the Germline piRNA Pathway. Mol Cell 50: 749761.

Dietzl, G., D. Chen, F. Schnorrer, K. C. Su, Y. Barinova et al., 2007 A genome-wide transgenic RNAi library for conditional gene inactivation in Drosophila. Nature 448: 151-156.

Durdevic, Z., R. S. Pillai and A. Ephrussi, 2018 Transposon silencing in the Drosophila female germline is essential for genome stability in progeny embryos. Life Sci Alliance 1: e201800179. 
Ejsmont, R. K., M. Bogdanzaliewa, K. A. Lipinski and P. Tomancak, 2011 Production of fosmid genomic libraries optimized for liquid culture recombineering and cross-species transgenesis. Methods Mol Biol 772: 423-443.

ElMaghraby, M. F., P. R. Andersen, F. Puhringer, U. Hohmann, K. Meixner et al., 2019 A Heterochromatin-Specific RNA Export Pathway Facilitates piRNA Production. Cell 178: 964-979 e920.

Fedoroff, N. V., 2012 Presidential address. Transposable elements, epigenetics, and genome evolution. Science 338: 758-767.

Feschotte, C., 2008 Transposable elements and the evolution of regulatory networks. Nat Rev Genet 9: 397-405.

Gareau, J. R., and C. D. Lima, 2010 The SUMO pathway: emerging mechanisms that shape specificity, conjugation and recognition. Nat Rev Mol Cell Biol 11: 861-871.

Goriaux, C., S. Desset, Y. Renaud, C. Vaury and E. Brasset, 2014 Transcriptional properties and splicing of the flamenco piRNA cluster. EMBO Rep 15: 411-418.

Grieder, N. C., M. de Cuevas and A. C. Spradling, 2000 The fusome organizes the microtubule network during oocyte differentiation in Drosophila. Development 127: 4253-4264.

Haley, B., D. Hendrix, V. Trang and M. Levine, 2008 A simplified miRNA-based gene silencing method for Drosophila melanogaster. Dev Biol 321: 482-490.

Handler, D., K. Meixner, M. Pizka, K. Lauss, C. Schmied et al., 2013 The Genetic Makeup of the Drosophila piRNA Pathway. Mol Cell 50: 762-777.

Hayashi, R., J. Schnabl, D. Handler, F. Mohn, S. L. Ameres et al., 2016 Genetic and mechanistic diversity of piRNA 3'-end formation. Nature 539: 588-592.

He, L., X. Wang and D. J. Montell, 2011 Shining light on Drosophila oogenesis: live imaging of egg development. Curr Opin Genet Dev 21: 612-619.

Heath, C. G., N. Viphakone and S. A. Wilson, 2016 The role of TREX in gene expression and disease. Biochem J 473: 2911-2935.

Horne-Badovinac, S., and D. Bilder, 2005 Mass transit: epithelial morphogenesis in the Drosophila egg chamber. Dev Dyn 232: 559-574.

Houwing, S., L. M. Kamminga, E. Berezikov, D. Cronembold, A. Girard et al., 2007 A role for Piwi and piRNAs in germ cell maintenance and transposon silencing in Zebrafish. Cell 129: 69-82. 
Hudson, A. M., and L. Cooley, 2014 Methods for studying oogenesis. Methods 68: 207-217.

Hur, J. K., Y. Luo, S. Moon, M. Ninova, G. K. Marinov et al., 2016 Splicing-independent loading of TREX on nascent RNA is required for efficient expression of dual-strand piRNA clusters in Drosophila. Genes Dev 30: 840-855.

Jentsch, S., and I. Psakhye, 2013 Control of nuclear activities by substrate-selective and proteingroup SUMOylation. Annu Rev Genet 47: 167-186.

Klattenhoff, C., D. P. Bratu, N. McGinnis-Schultz, B. S. Koppetsch, H. A. Cook et al., 2007 Drosophila rasiRNA pathway mutations disrupt embryonic axis specification through activation of an ATR/Chk2 DNA damage response. Dev Cell 12: 45-55.

Klattenhoff, C., H. Xi, C. Li, S. Lee, J. Xu et al., 2009 The Drosophila HP1 homolog Rhino is required for transposon silencing and piRNA production by dual-strand clusters. Cell 138: 1137-1149.

Kneuss, E., M. Munafo, E. L. Eastwood, U. S. Deumer, J. B. Preall et al., 2019 Specialization of the Drosophila nuclear export family protein Nxf3 for piRNA precursor export. Genes Dev 33: 1208-1220.

Kohler, A., and E. Hurt, 2007 Exporting RNA from the nucleus to the cytoplasm. Nat Rev Mol Cell Biol 8: 761-773.

Lau, N. C., N. Robine, R. Martin, W. J. Chung, Y. Niki et al., 2009 Abundant primary piRNAs, endo-siRNAs, and microRNAs in a Drosophila ovary cell line. Genome Res.

Le Thomas, A., A. K. Rogers, A. Webster, G. K. Marinov, S. E. Liao et al., 2013 Piwi induces piRNA-guided transcriptional silencing and establishment of a repressive chromatin state. Genes Dev 27: 390-399.

Luo, Y., E. Fefelova, M. Ninova, Y. A. Chen and A. A. Aravin, 2020 Repression of interrupted and intact rDNA by the SUMO pathway in Drosophila melanogaster. Elife 9.

Malone, C. D., J. Brennecke, M. Dus, A. Stark, W. R. McCombie et al., 2009 Specialized piRNA pathways act in germline and somatic tissues of the Drosophila ovary. Cell 137: 522-535.

Malone, C. D., and G. J. Hannon, 2009 Small RNAs as guardians of the genome. Cell 136: 656668.

Mohn, F., G. Sienski, D. Handler and J. Brennecke, 2014 The rhino-deadlock-cutoff complex licenses noncanonical transcription of dual-strand piRNA clusters in Drosophila. Cell 157: 1364-1379. 
Ni, J. Q., M. Markstein, R. Binari, B. Pfeiffer, L. P. Liu et al., 2008 Vector and parameters for targeted transgenic RNA interference in Drosophila melanogaster. Nat Methods 5: 49-51.

Ni, J. Q., R. Zhou, B. Czech, L. P. Liu, L. Holderbaum et al., 2011 A genome-scale shRNA resource for transgenic RNAi in Drosophila. Nat Methods 8: 405-407.

Ninova, M., Y. A. Chen, B. Godneeva, A. K. Rogers, Y. Luo et al., 2020 Su(var)2-10 and the SUMO Pathway Link piRNA-Guided Target Recognition to Chromatin Silencing. Mol Cell 77: 556-570 e556.

Ninova, M., K. Fejes Toth and A. A. Aravin, 2019 The control of gene expression and cell identity by H3K9 trimethylation. Development 146.

Olivieri, D., M. M. Sykora, R. Sachidanandam, K. Mechtler and J. Brennecke, 2010 An in vivo RNAi assay identifies major genetic and cellular requirements for primary piRNA biogenesis in Drosophila. EMBO J 29: 3301-3317.

Ozata, D. M., I. Gainetdinov, A. Zoch, D. O'Carroll and P. D. Zamore, 2018 PIWI-interacting RNAs: small RNAs with big functions. Nat Rev Genet.

Pane, A., K. Wehr and T. Schupbach, 2007 zucchini and squash encode two putative nucleases required for rasiRNA production in the Drosophila germline. Dev Cell 12: 851-862.

Puhringer, T., U. Hohmann, L. Fin, B. Pacheco-Fiallos, U. Schellhaas et al., 2020 Structure of the human core transcription-export complex reveals a hub for multivalent interactions. Elife 9.

Rozhkov, N. V., M. Hammell and G. J. Hannon, 2013 Multiple roles for Piwi in silencing Drosophila transposons. Genes Dev 27: 400-412.

Schindelin, J., I. Arganda-Carreras, E. Frise, V. Kaynig, M. Longair et al., 2012 Fiji: an opensource platform for biological-image analysis. Nat Methods 9: 676-682.

Schupbach, T., and S. Roth, 1994 Dorsoventral patterning in Drosophila oogenesis. Curr Opin Genet Dev 4: 502-507.

Senti, K. A., D. Jurczak, R. Sachidanandam and J. Brennecke, 2015 piRNA-guided slicing of transposon transcripts enforces their transcriptional silencing via specifying the nuclear piRNA repertoire. Genes Dev 29: 1747-1762.

Sienski, G., J. Batki, K. A. Senti, D. Donertas, L. Tirian et al., 2015 Silencio/CG9754 connects the Piwi-piRNA complex to the cellular heterochromatin machinery. Genes Dev 29: 2258-2271.

Sienski, G., D. Donertas and J. Brennecke, 2012 Transcriptional silencing of transposons by Piwi and maelstrom and its impact on chromatin state and gene expression. Cell 151: 964-980. 
Siomi, M. C., K. Sato, D. Pezic and A. A. Aravin, 2011 PIWI-interacting small RNAs: the vanguard of genome defence. Nat Rev Mol Cell Biol 12: 246-258.

Staller, M. V., D. Yan, S. Randklev, M. D. Bragdon, Z. B. Wunderlich et al., 2013 Depleting gene activities in early Drosophila embryos with the "maternal-Gal4-shRNA" system. Genetics 193: 51-61.

Tanentzapf, G., D. Devenport, D. Godt and N. H. Brown, 2007 Integrin-dependent anchoring of a stem-cell niche. Nat Cell Biol 9: 1413-1418.

Telley, I. A., I. Gaspar, A. Ephrussi and T. Surrey, 2012 Aster migration determines the length scale of nuclear separation in the Drosophila syncytial embryo. J Cell Biol 197: 887-895.

Theurkauf, W. E., C. Klattenhoff, D. P. Bratu, N. McGinnis-Schultz, B. S. Koppetsch et al., 2006 rasiRNAs, DNA damage, and embryonic axis specification. Cold Spring Harb Symp Quant Biol 71: 171-180.

Venken, K. J., J. W. Carlson, K. L. Schulze, H. Pan, Y. He et al., 2009 Versatile P[acman] BAC libraries for transgenesis studies in Drosophila melanogaster. Nat Methods 6: 431-434.

Wang, L., K. Dou, S. Moon, F. J. Tan and Z. Z. Zhang, 2018 Hijacking Oogenesis Enables Massive Propagation of LINE and Retroviral Transposons. Cell 174: 1082-1094 e1012.

Wang, S. H., and S. C. Elgin, 2011 Drosophila Piwi functions downstream of piRNA production mediating a chromatin-based transposon silencing mechanism in female germ line. Proc Natl Acad Sci U S A 108: 21164-21169.

Wehr, K., A. Swan and T. Schupbach, 2006 Deadlock, a novel protein of Drosophila, is required for germline maintenance, fusome morphogenesis and axial patterning in oogenesis and associates with centrosomes in the early embryo. Dev Biol 294: 406-417.

Yan, D., R. A. Neumuller, M. Buckner, K. Ayers, H. Li et al., 2014 A regulatory network of Drosophila germline stem cell self-renewal. Dev Cell 28: 459-473.

Yu, Y., J. Gu, Y. Jin, Y. Luo, J. B. Preall et al., 2015 Panoramix enforces piRNA-dependent cotranscriptional silencing. Science 350: 339-342.

Zamparini, A. L., M. Y. Davis, C. D. Malone, E. Vieira, J. Zavadil et al., 2011 Vreteno, a gonadspecific protein, is essential for germline development and primary piRNA biogenesis in Drosophila. Development 138: 4039-4050.

Zhang, F., J. Wang, J. Xu, Z. Zhang, B. S. Koppetsch et al., 2012 UAP56 couples piRNA clusters to the perinuclear transposon silencing machinery. Cell 151:871-884. 
bioRxiv preprint doi: https://doi.org/10.1101/2021.06.29.450424; this version posted July 1, 2021. The copyright holder for this preprint (which

was not certified by peer review) is the author/funder, who has granted bioRxiv a license to display the preprint in perpetuity. It is made available under aCC-BY-NC-ND 4.0 International license.

Zhang, G., S. Tu, T. Yu, X. O. Zhang, S. S. Parhad et al., 2018 Co-dependent Assembly of Drosophila piRNA Precursor Complexes and piRNA Cluster Heterochromatin. Cell Rep 24: 3413-3422 e3414.

Zhang, Z., J. Wang, N. Schultz, F. Zhang, S. S. Parhad et al., 2014 The HP1 homolog rhino anchors a nuclear complex that suppresses piRNA precursor splicing. Cell 157: 1353-1363. 


\section{Table 1. MTD-Gal4 reporter lines}

\begin{tabular}{|c|c|c|c|c|}
\hline \multirow{5}{*}{ 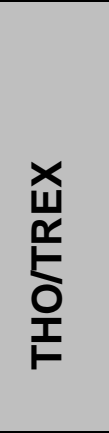 } & Name & $\begin{array}{l}\text { Gene } \\
\text { name }\end{array}$ & CG Number & Source \\
\hline & MTD-Gal4 + Thoc5-GFP & thoc5 & CG2980 & This paper \\
\hline & MTD-Gal4 + GFP-Thoc7 & thoc7 & CG17143 & This paper \\
\hline & MTD-Gal4 + GFP-Tho2 & Tho2 & CG31671 & This paper \\
\hline & MTD-Gal4 + GFP-UAP56 & Hel25E & CG7269 & ElMaghraby et al., 2019 \\
\hline \multirow{6}{*}{ 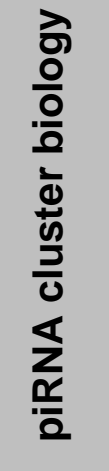 } & MTD-Gal4 + GFP-Rhino & rhi & CG10683 & Mohn et al., 2014 \\
\hline & MTD-Gal4 + GFP-Deadlock & cuff & CG13190 & Mohn et al., 2014 \\
\hline & MTD-Gal4 + GFP-Cutoff & del & CG9252 & Mohn et al., 2014 \\
\hline & MTD-Gal4 + GFP-Moonshiner & moon & CG12721 & ElMaghraby et al., 2019 \\
\hline & MTD-Gal4 + GFP-Nxf3 & $n \times f 3$ & CG32135 & EIMaghraby et al., 2019 \\
\hline & MTD-Gal4 + GFP-Bootlegger & boot & CG13741 & ElMaghraby et al., 2019 \\
\hline \multirow{6}{*}{ 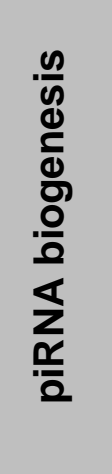 } & MTD-Gal4 + GFP-Zucchini & $z u c$ & CG12314 & Hayashi et al., 2016 \\
\hline & MTD-Gal4 + GFP-Gasz & Gasz & CG2183 & This paper \\
\hline & MTD-Gal4 + GFP-Vasa & vas & CG46283 & This paper \\
\hline & MTD-Gal4 + GFP-Aubergine & spn-E & CG3158 & This paper \\
\hline & MTD-Gal4 + GFP-Spindle E & $a u b$ & CG6137 & This paper \\
\hline & MTD-Gal4 + GFP-Nibbler & Nbr & CG9247 & This paper \\
\hline \multirow{8}{*}{ 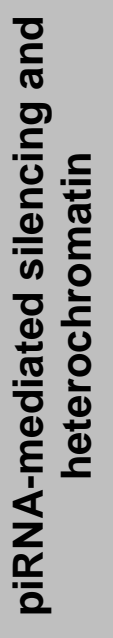 } & MTD-Gal4 + GFP-Nxf2 & $n \times f 2$ & CG4118 & This paper \\
\hline & MTD-Gal4 + GFP-Gtsf1 & $\operatorname{arx}$ & CG3893 & This paper \\
\hline & MTD-Gal4 + GFP-Panoramix & Panx & CG9754 & This paper \\
\hline & MTD-Gal4 + GFP-Piwi & piwi & CG6122 & This paper \\
\hline & MTD-Gal4 + GFP-Sov & sov & CG14438 & This paper \\
\hline & MTD-Gal4 + GFP-HP1 & Su(var)3-9 & CG43664 & This paper \\
\hline & MTD-Gal4 + GFP-Eggless & egg & CG12196 & This paper \\
\hline & MTD-Gal4 + silencing reporter & & & Sienski et al., 2015 \\
\hline
\end{tabular}


bioRxiv preprint doi: https://doi.org/10.1101/2021.06.29.450424; this version posted July 1, 2021. The copyright holder for this preprint (which was not certified by peer review) is the author/funder, who has granted bioRxiv a license to display the preprint in perpetuity. It is made available under aCC-BY-NC-ND 4.0 International license. 
bioRxiv preprint doi: https://doi.org/10.1101/2021.06.29.450424; this version posted July 1, 2021. The copyright holder for this preprint (which was not certified by peer review) is the author/funder, who has granted bioRxiv a license to display the preprint in perpetuity. It is made available under aCC-BY-NC-ND 4.0 International license.

Figure 1

A
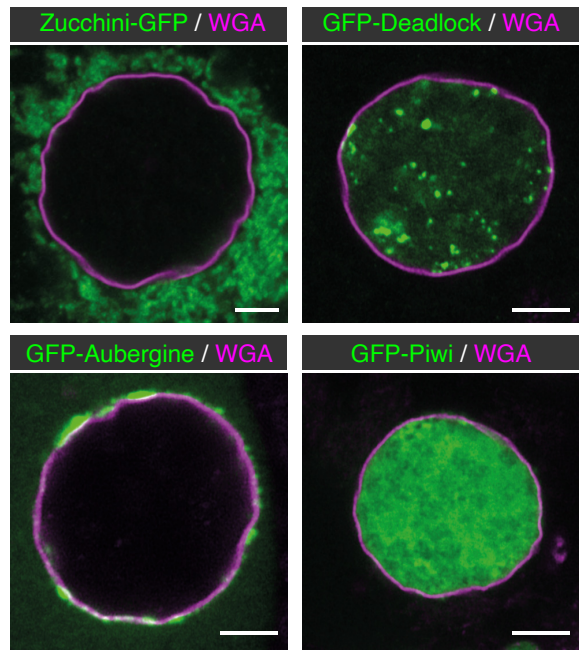

B

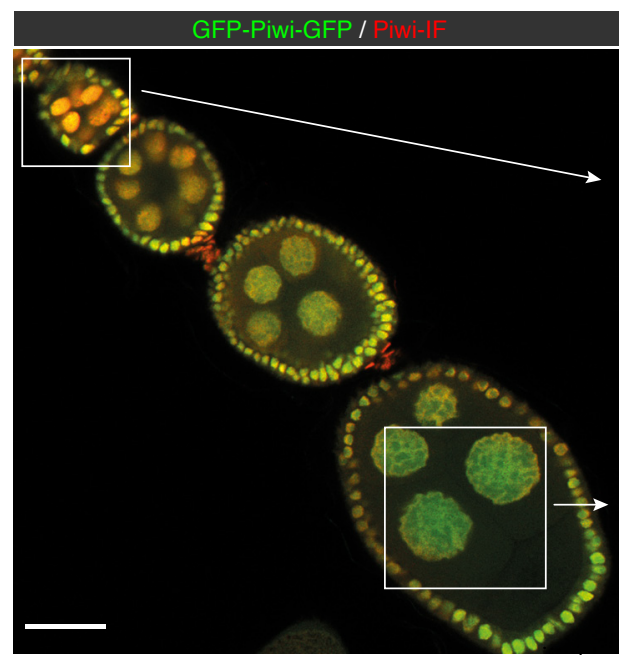

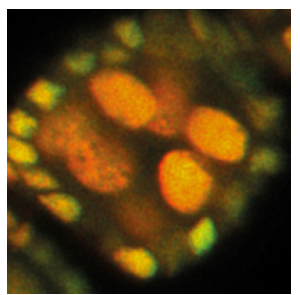

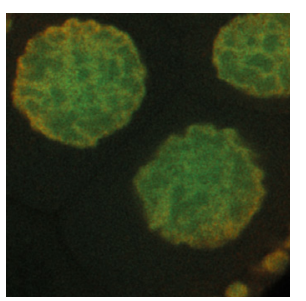

C
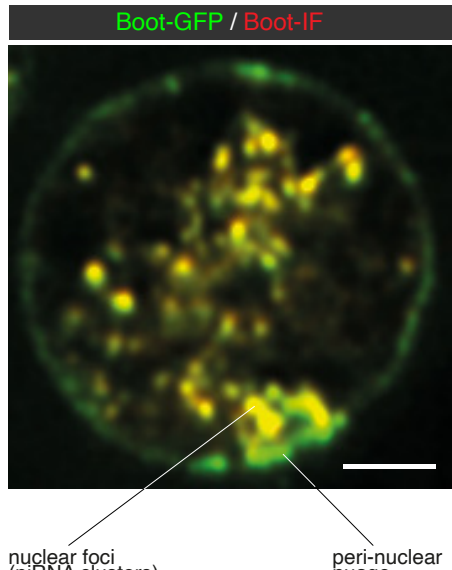

$\mathrm{E}$
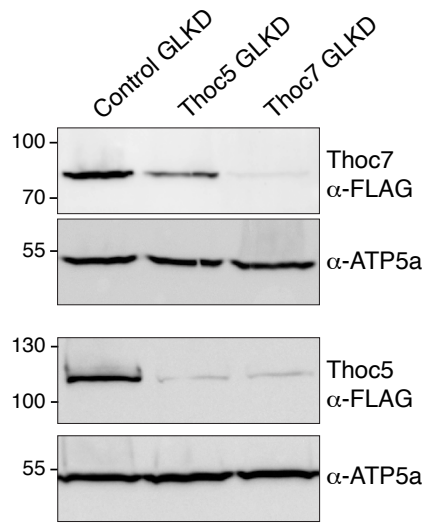

$\mathrm{F}$

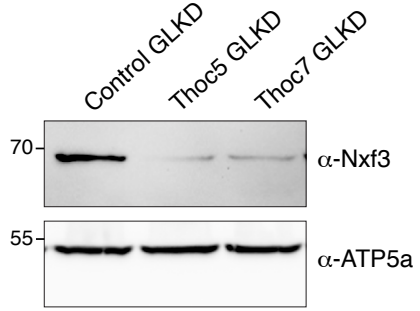

D
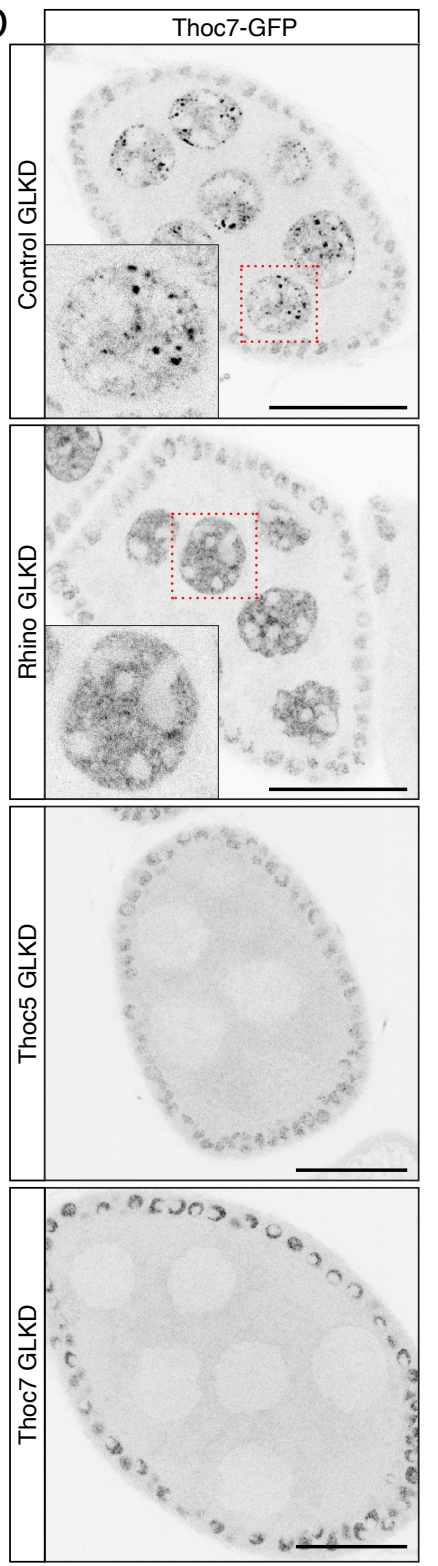
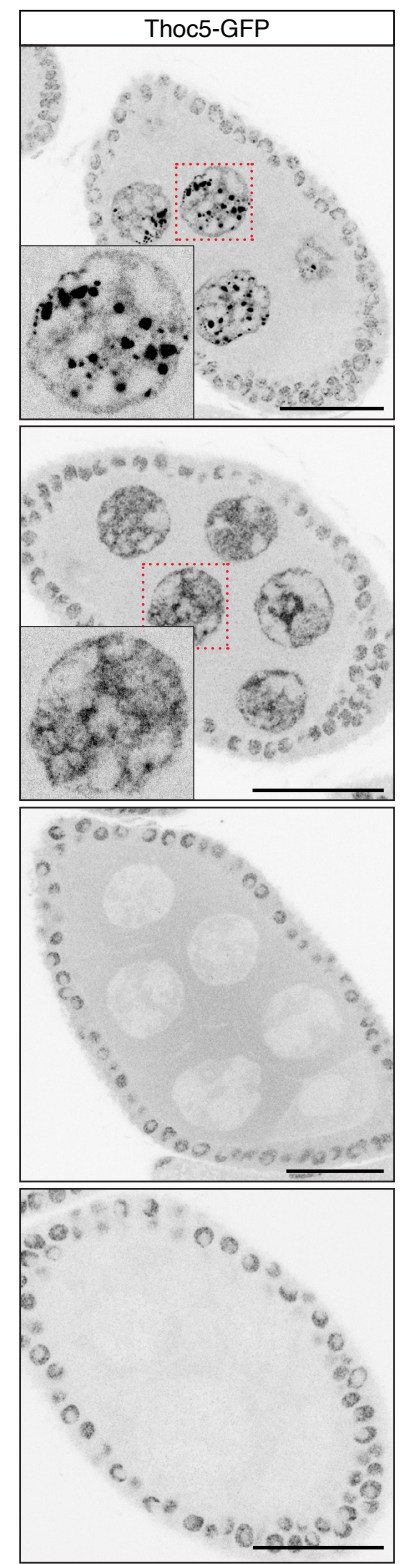

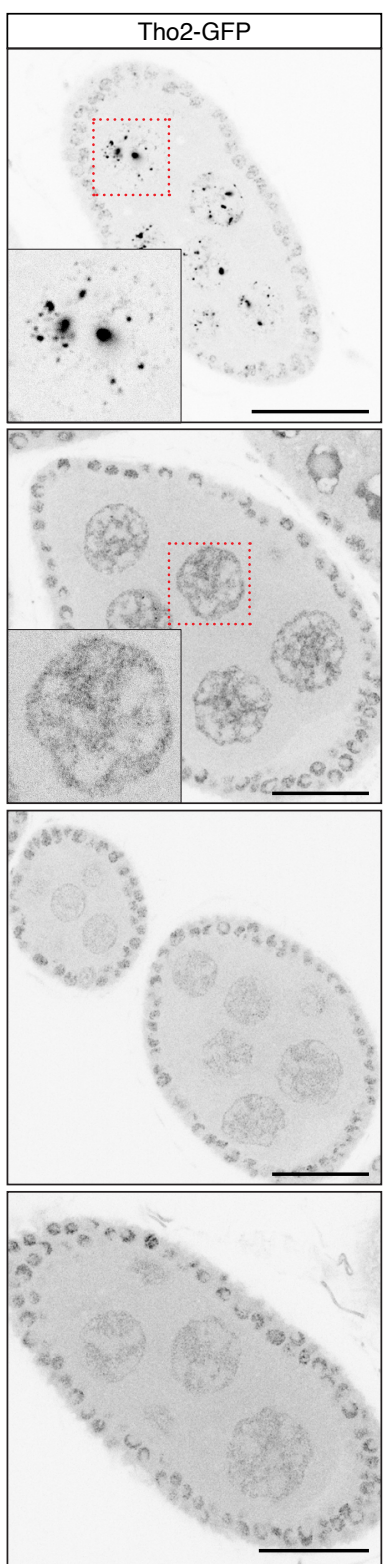


bioRxiv preprint doi: https://doi.org/10.1101/2021.06.29.450424; this version posted July 1, 2021. The copyright holder for this preprint (which was not certified by peer review) is the author/funder, who has granted bioRxiv a license to display the preprint in perpetuity. It is made available under aCC-BY-NC-ND 4.0 International license.

\section{Figure 2}

A

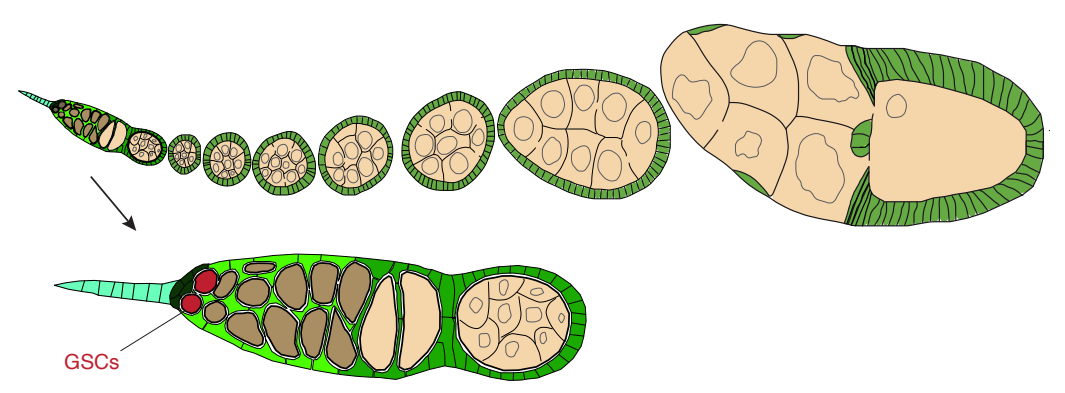

regions \begin{tabular}{|l|l|l|l|l|}
1 & $2 \mathrm{~A}$ & $2 \mathrm{~B}$ & 3 & $\mathbf{3}$
\end{tabular}

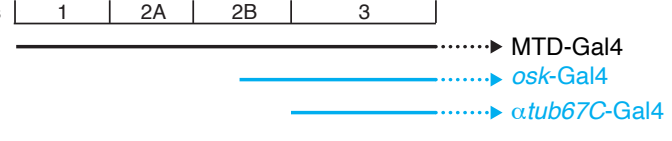

C

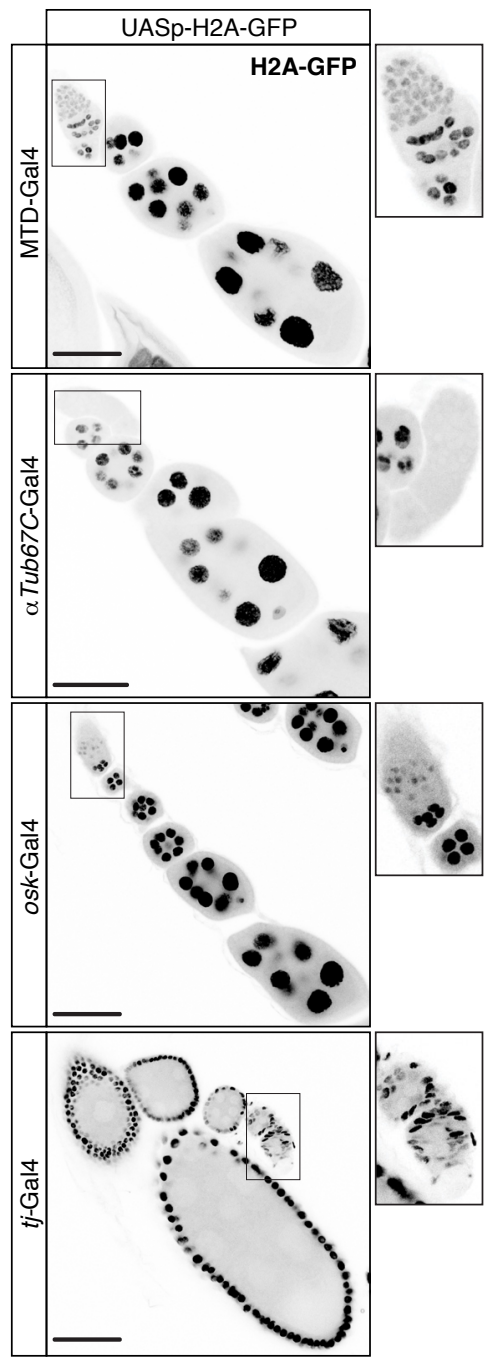

D

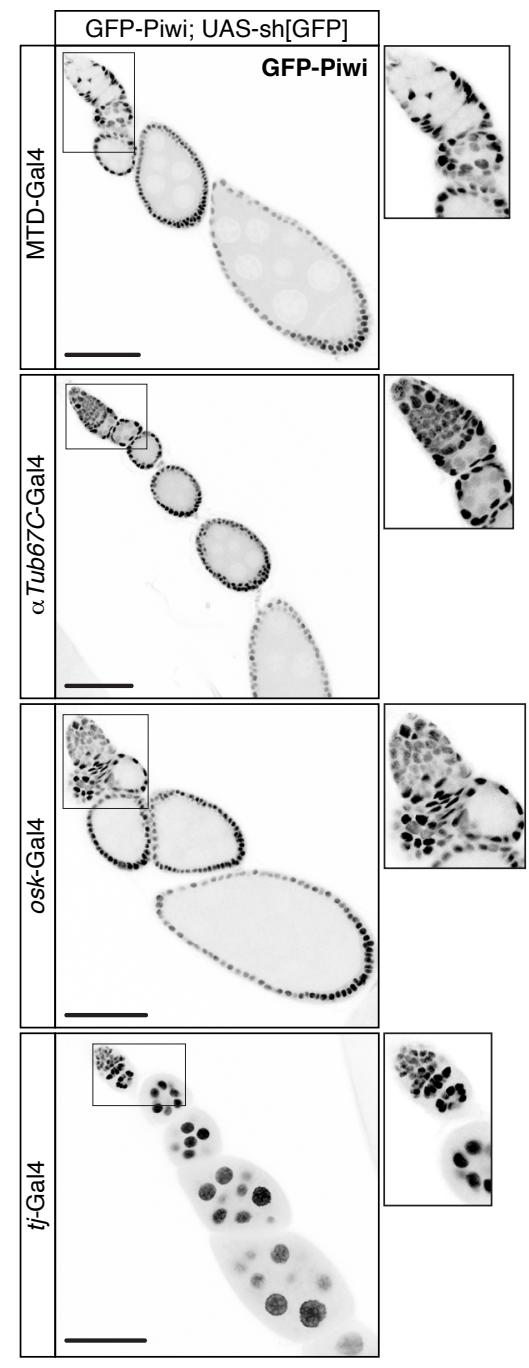

B

UASp-H2A-GFP crossed to

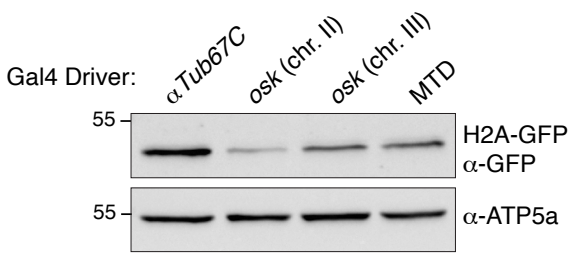

E

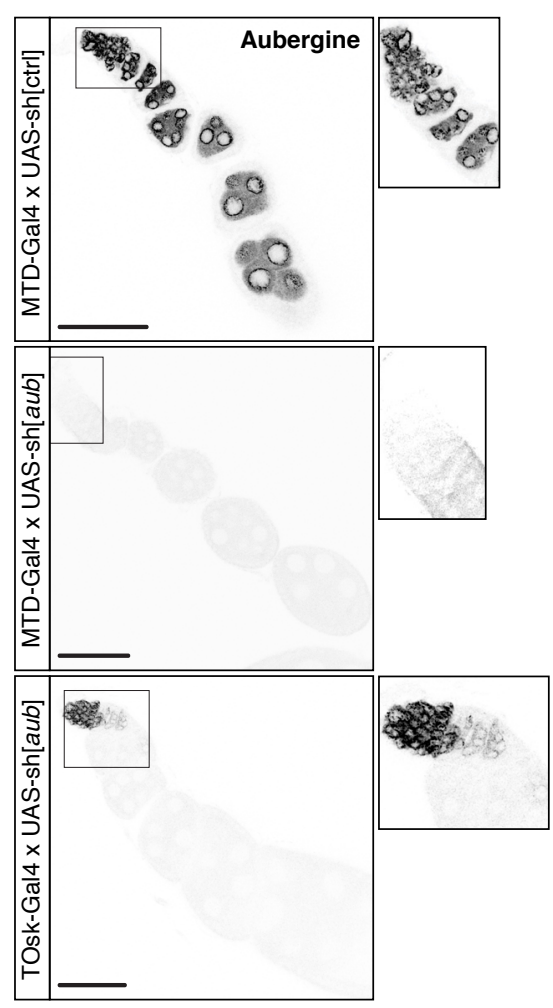

Gal4 Driver: MTD-GAL4 TOsk-GAL4

shRNA line:

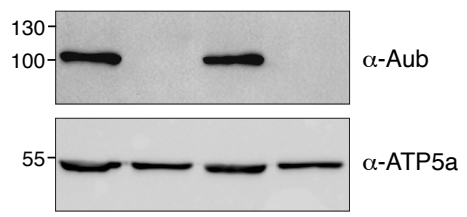


bioRxiv preprint doi: https://doi.org/10.1101/2021.06.29.450424; this version posted July 1, 2021. The copyright holder for this preprint (which was not certified by peer review) is the author/funder, who has granted bioRxiv a license to display the preprint in perpetuity. It is made available under aCC-BY-NC-ND 4.0 International license.

\section{Figure 3}

A

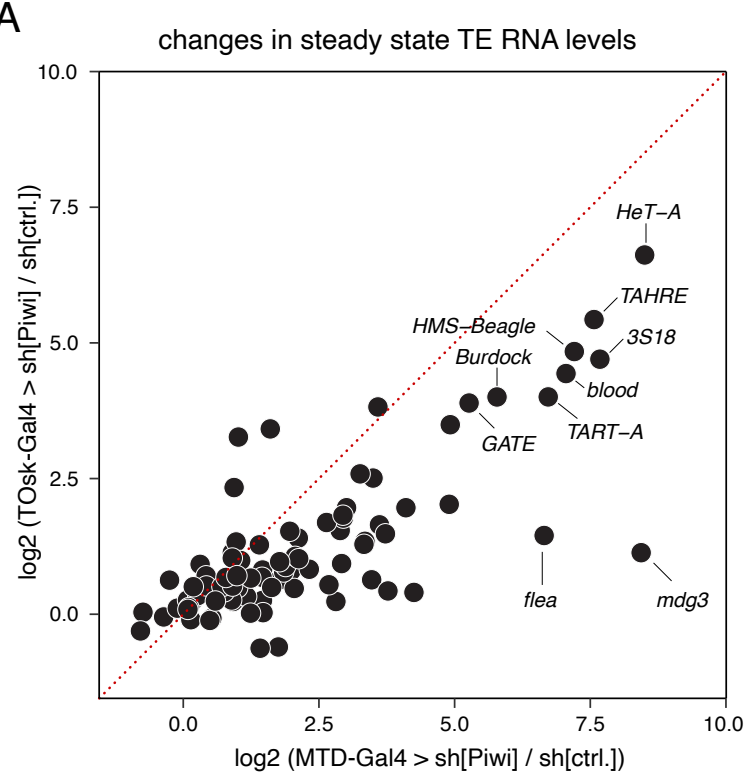

C

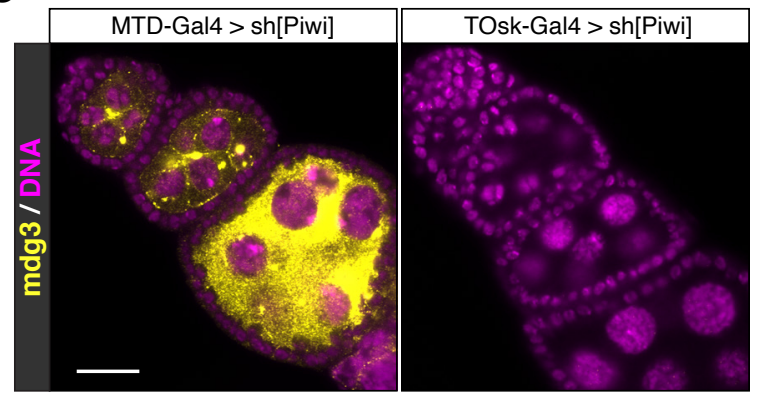

B
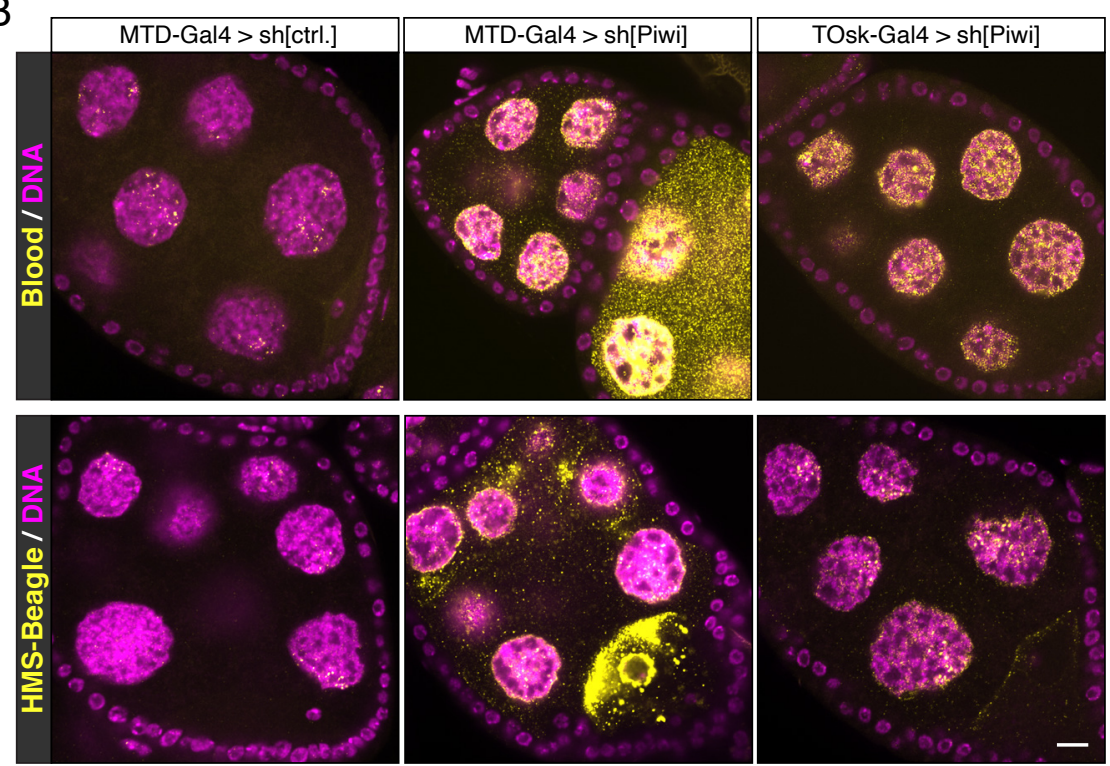
bioRxiv preprint doi: https://doi.org/10.1101/2021.06.29.450424; this version posted July 1, 2021. The copyright holder for this preprint (which was not certified by peer review) is the author/funder, who has granted bioRxiv a license to display the preprint in perpetuity. It is made available under aCC-BY-NC-ND 4.0 International license.

Figure 4
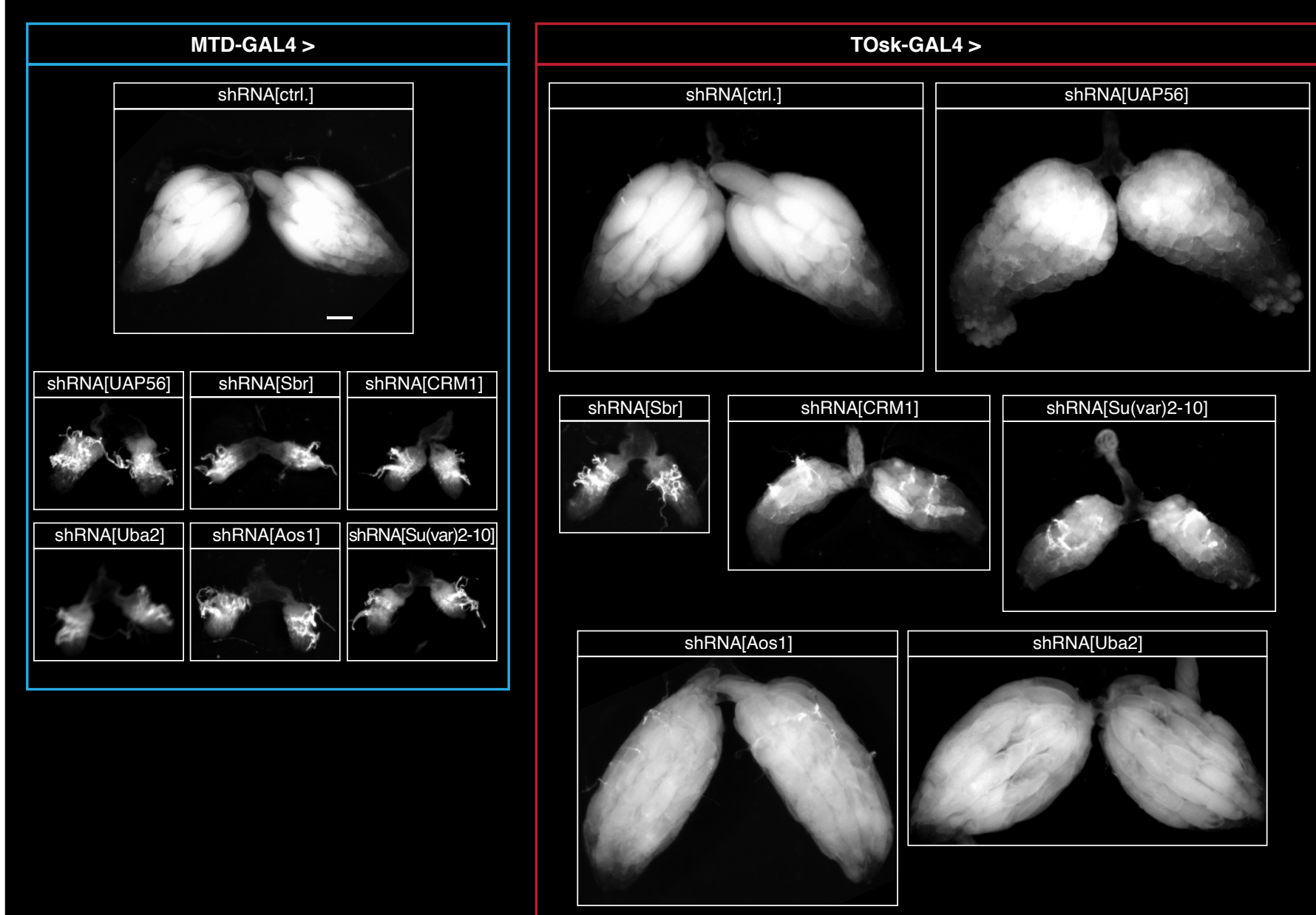
bioRxiv preprint doi: https://doi org/10.1101/2021.06.29.450424; this version posted July 1, 2021. The copyright holder for this preprint (which was not certified by peer review) is the author/funder, who has granted bioRxiv a license to display the preprint in perpetuity. It is made available under ACC-BY-NC-ND 4.0 International license.

\section{Figure 5}

A
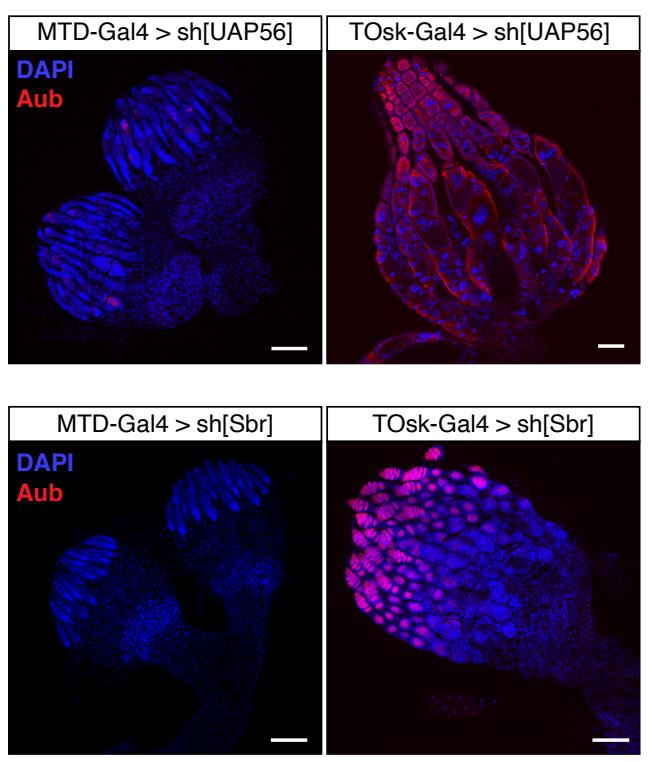

B

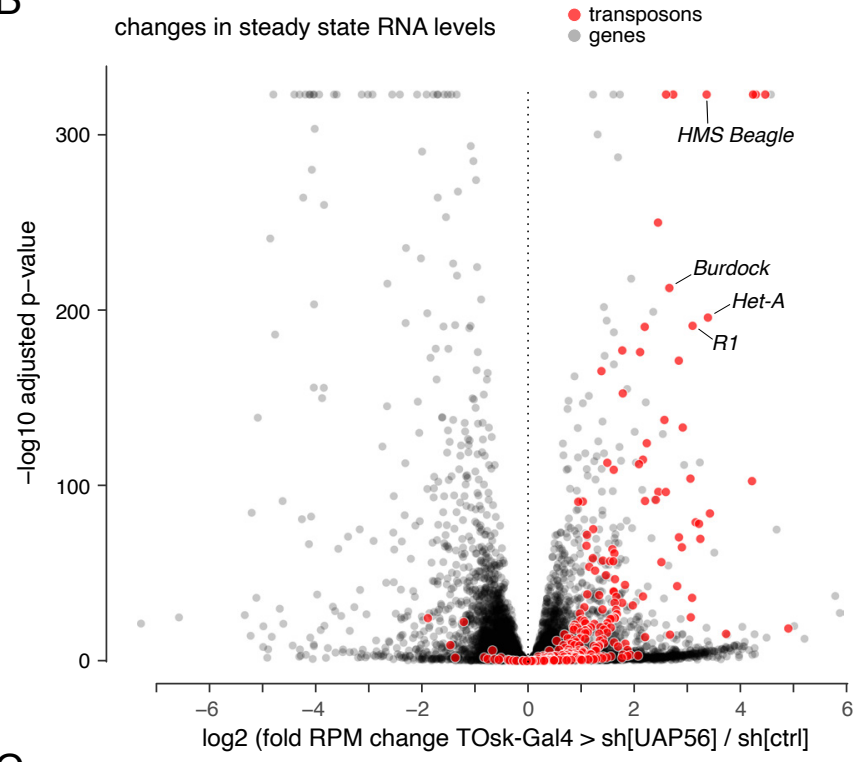

C

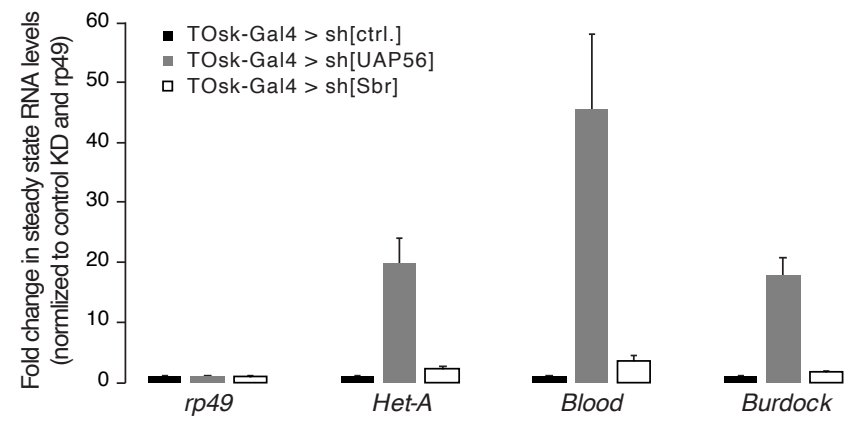


bioRxiv preprint doi: https://doi.org/10.1101/2021.06.29.450424; this version posted July 1, 2021. The copyright holder for this preprint (which was not certified by peer review) is the author/funder, who has granted bioRxiv a license to display the preprint in perpetuity. It is made available under aCC-BY-NC-ND 4.0 International license.

\section{Figure 6}

A

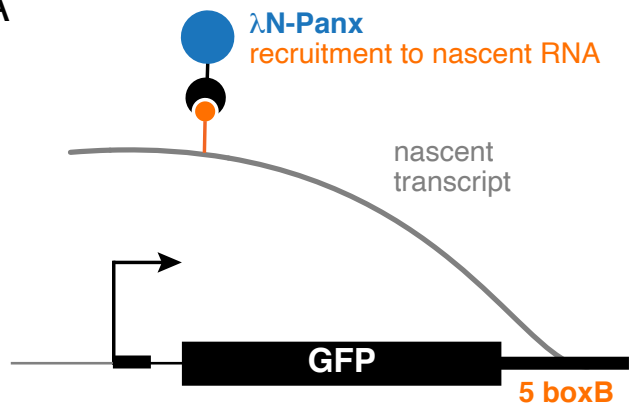

B

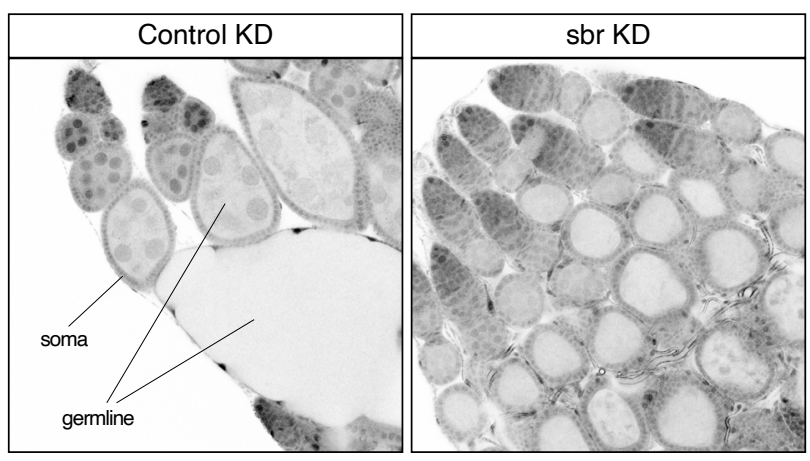

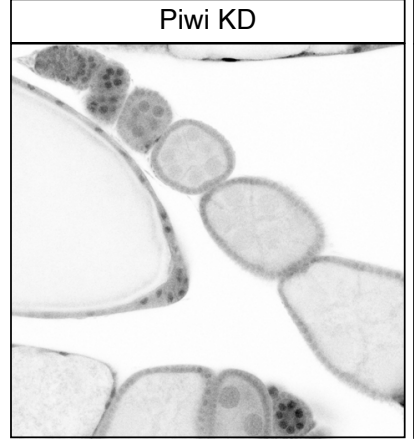

C

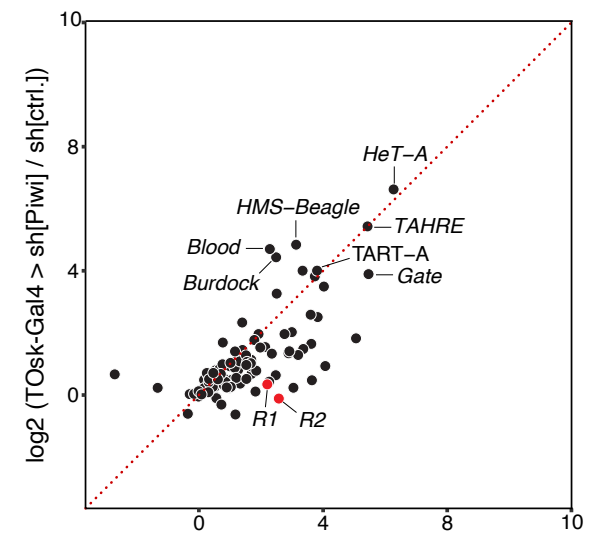

log2 (TOsk-Gal4 > sh[Su(var)2-10] / sh[ctrl.])
$\mathrm{D}$

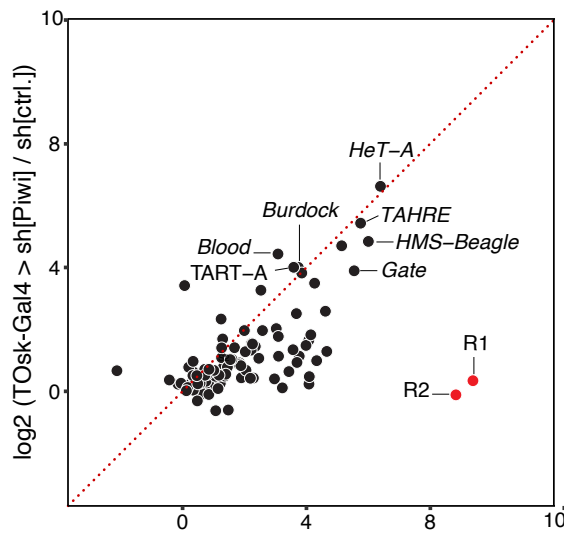

$\log 2$ (TOsk-Gal4 > sh[Aos1] / sh[ctrl.])

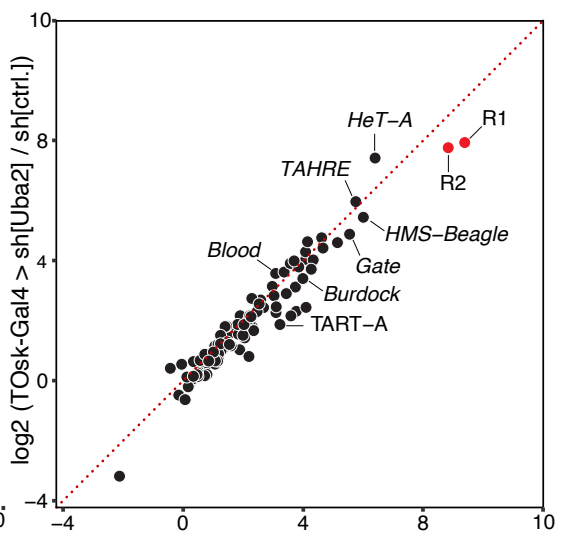

log2 (TOsk-Gal4 > sh[Aos1] / sh[ctrl.])

E
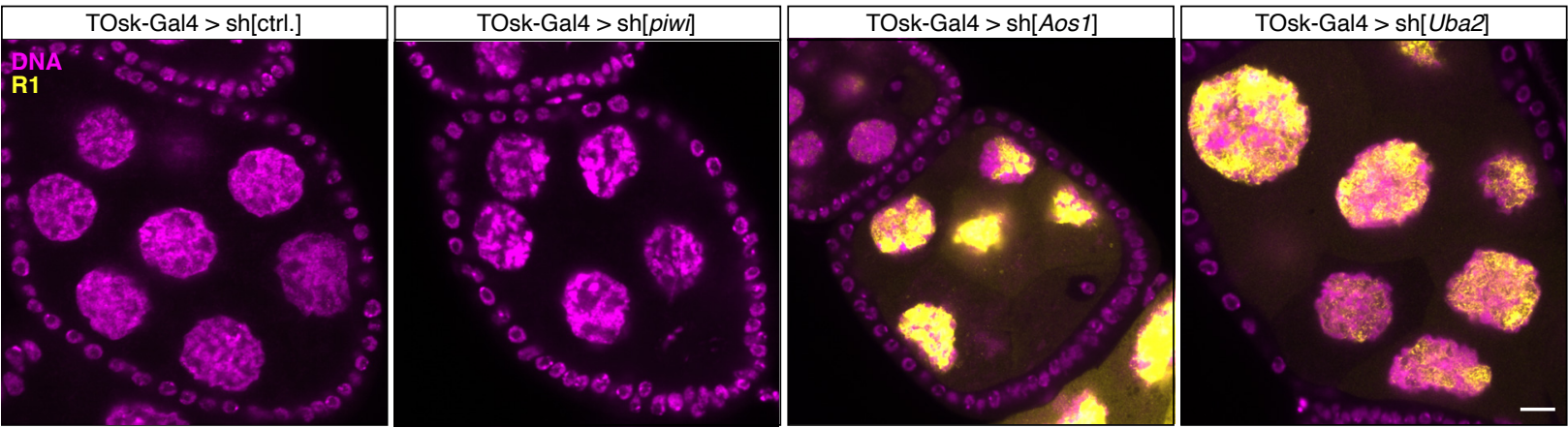
bioRxiv preprint doi: https://doi.org/10.1101/2021.06.29.450424; this version posted July 1, 2021. The copyright holder for this preprint (which was not certified by peer review) is the author/funder, who has granted bioRxiv a license to display the preprint in perpetuity. It is made available under aCC-BY-NC-ND 4.0 International license.

\section{Figure 7}

A
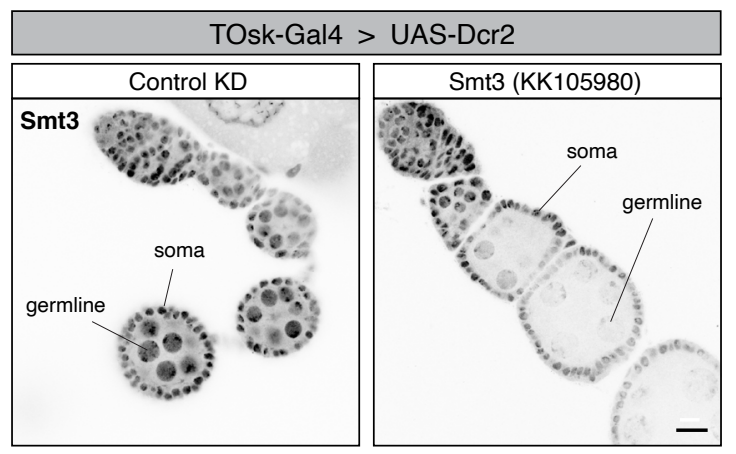

C

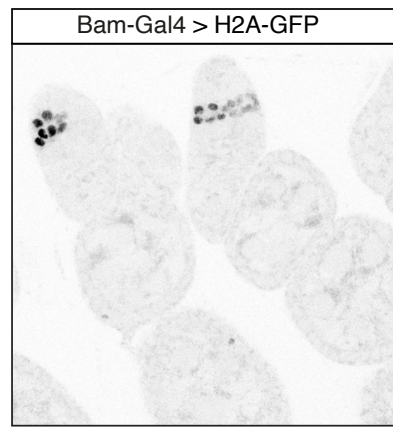

D BamTOsk-Gal4; GFP-Piwi > sh[GFP]

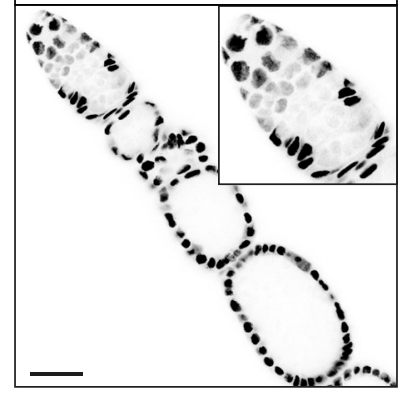

E

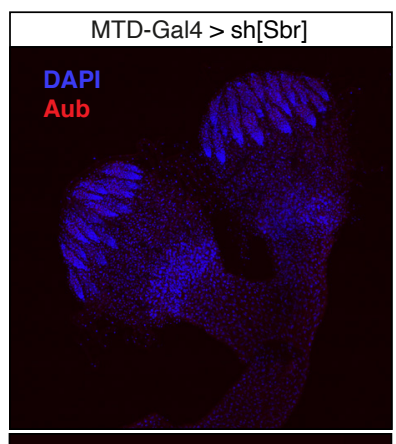

B

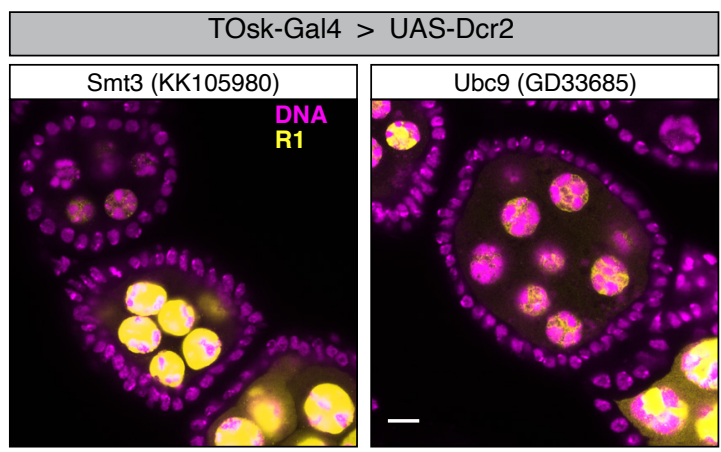

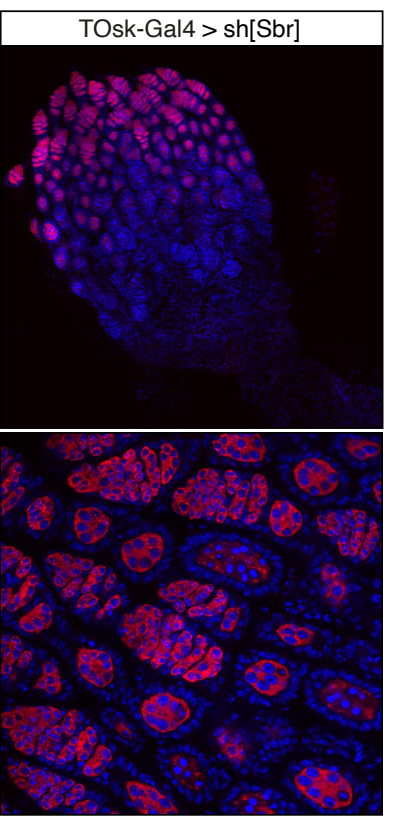

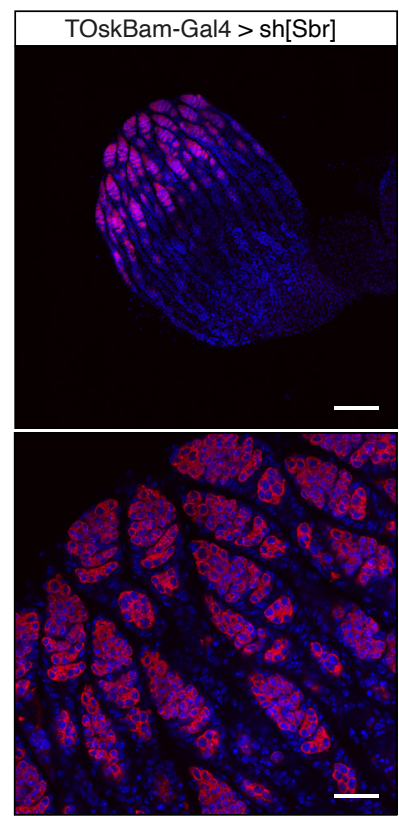


bioRxiv preprint doi: https://doi.org/10.1101/2021.06.29.450424; this version posted July 1, 2021. The copyright holder for this preprint (which

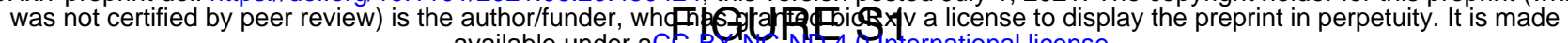
available under act-BY-NE-O international license.

A

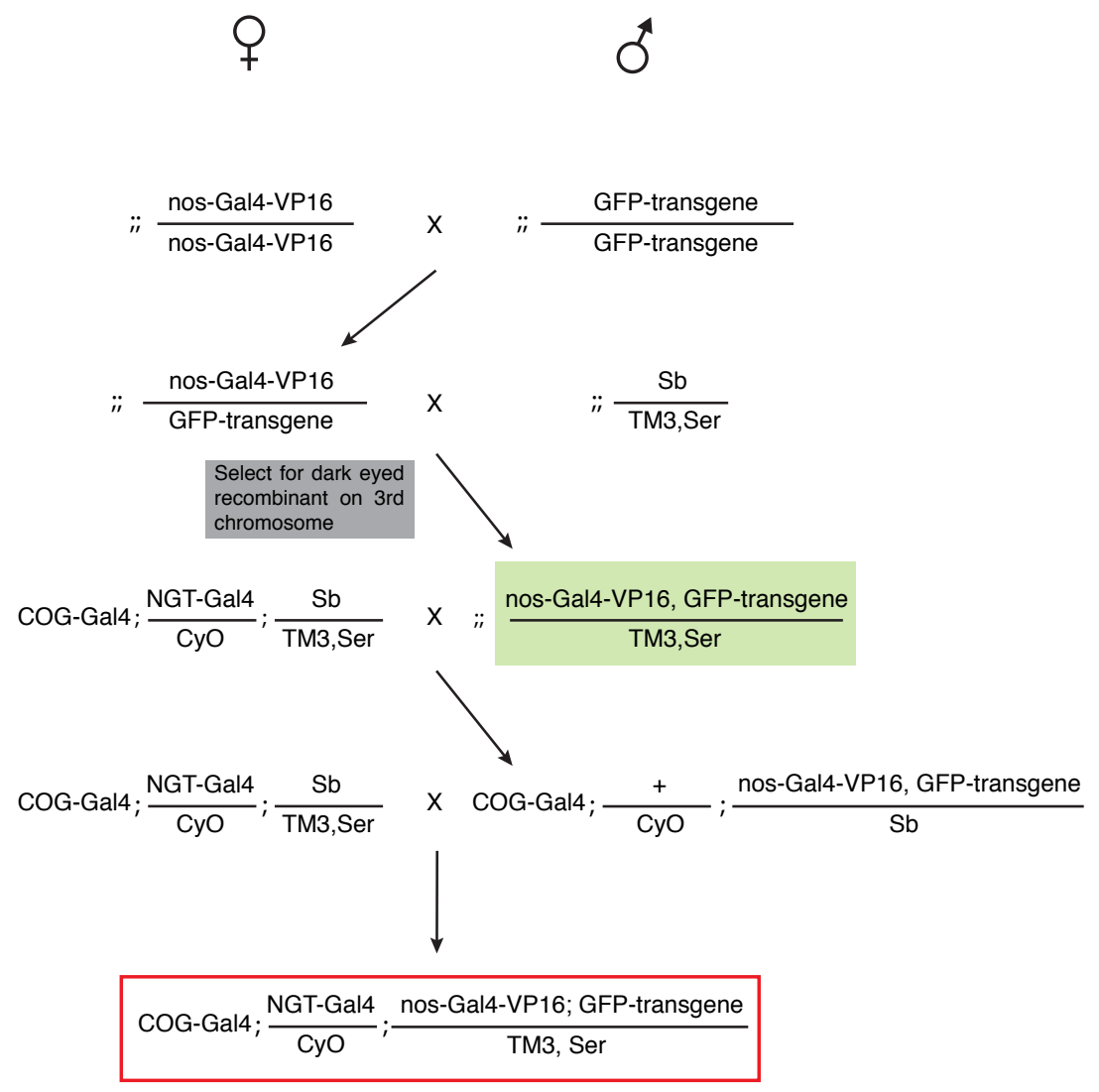

B

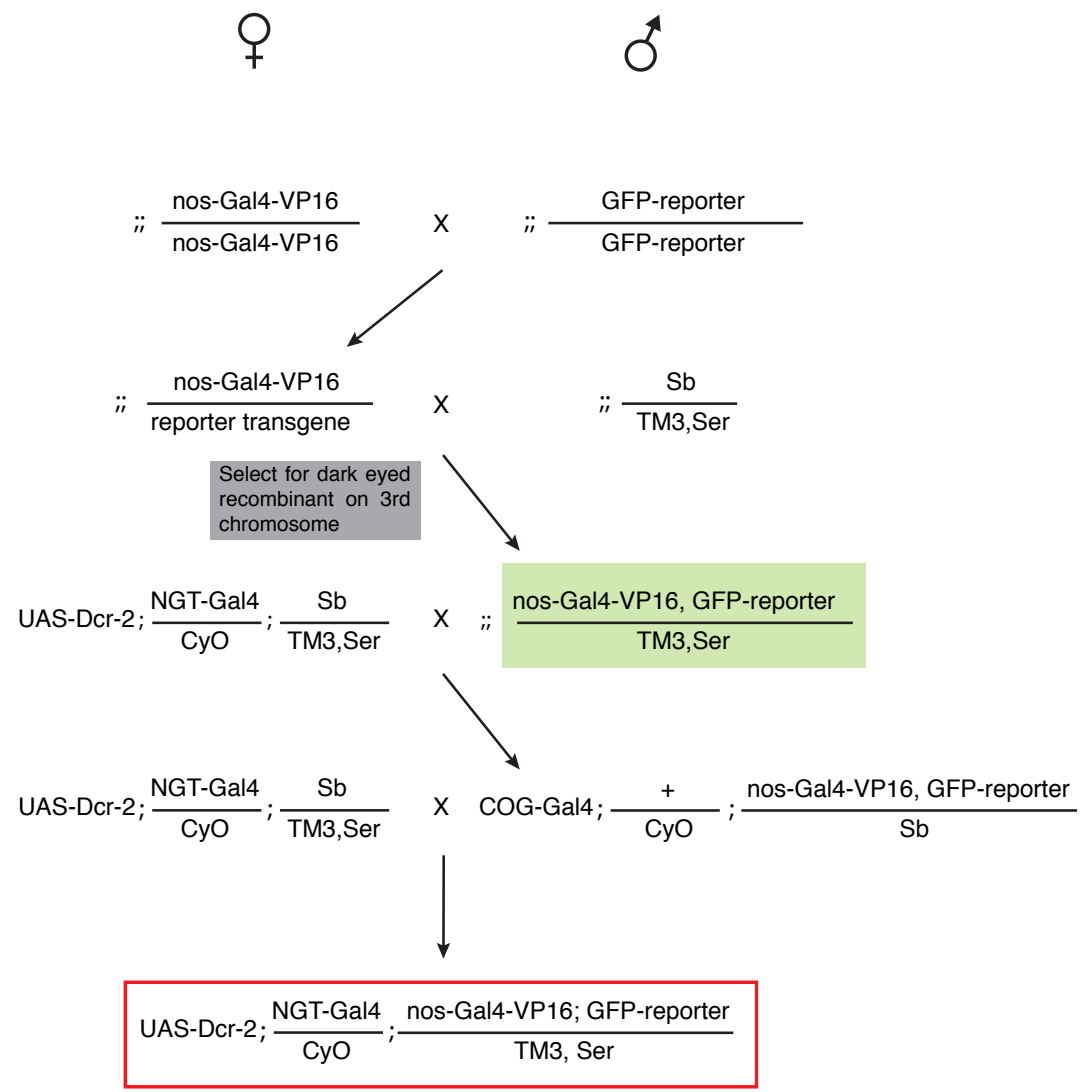

